\title{
Self-Control in Cyberspace: Applying Dual Systems Theory to a Review of Digital Self-Control Tools
}

\author{
Ulrik Lyngs \\ ulrik.lyngs@cs.ox.ac.uk \\ Department of Computer Science, \\ University of Oxford \\ Oxford, United Kingdom \\ Reuben Binns \\ Adam Slack \\ reuben.binns@cs.ox.ac.uk \\ AdamSlack@outlook.com \\ Department of Computer Science, \\ University of Oxford \\ Oxford, United Kingdom
}

\author{
Kai Lukoff \\ kai1@uw.edu \\ Human Centered Design \& \\ Engineering, \\ University of Washington \\ Seattle, USA
}

\author{
Michael Inzlicht \\ michael.inzlicht@utoronto.ca \\ Department of Psychology, \\ University of Toronto \\ Toronto, Canada
}

\author{
Petr Slovak $^{*}$ \\ p.slovak@ucl.ac.uk \\ Department of Informatics, \\ King's College London \\ London, United Kingdom
}

\section{Max Van Kleek}

Nigel Shadbolt

max.van.kleek@cs.ox.ac.uk nigel.shadbolt@cs.ox.ac.uk

Department of Computer Science,

University of Oxford

Oxford, United Kingdom

\begin{abstract}
Many people struggle to control their use of digital devices. However, our understanding of the design mechanisms that support user self-control remains limited. In this paper, we make two contributions to $\mathrm{HCI}$ research in this space: first, we analyse 367 apps and browser extensions from the Google Play, Chrome Web, and Apple App stores to identify common core design features and intervention strategies afforded by current tools for digital self-control. Second, we adapt and apply an integrative dual systems model of self-regulation as a framework for organising and evaluating the design features found. Our analysis aims to help the design of better tools in two ways: (i) by identifying how, through a wellestablished model of self-regulation, current tools overlap and differ in how they support self-control; and (ii) by using the model to reveal underexplored cognitive mechanisms that could aid the design of new tools.
\end{abstract}

\section{CCS CONCEPTS}

- Human-centered computing $\rightarrow \mathrm{HCI}$ theory, concepts and models; Empirical studies in HCI.

\footnotetext{
*Also with UCL Interaction Centre, University College London.
}

CHI 2019, May 4-9, 2019, Glasgow, Scotland UK

( 2019 Copyright held by the owner/author(s). Publication rights licensed to ACM.

This is the author's version of the work. It is posted here for your personal use. Not for redistribution. The definitive Version of Record was published in CHI Conference on Human Factors in Computing Systems Proceedings (CHI 2019), May 4-9, 2019, Glasgow, Scotland UK, https://doi.org/10.1145/3290605. 3300361.

\section{KEYWORDS}

Attention; self-control; self-regulation; distraction; ICT nonuse; addiction; focus; interruptions

\section{ACM Reference Format:}

Ulrik Lyngs, Kai Lukoff, Petr Slovak, Reuben Binns, Adam Slack, Michael Inzlicht, Max Van Kleek, and Nigel Shadbolt. 2019. SelfControl in Cyberspace: Applying Dual Systems Theory to a Review of Digital Self-Control Tools. In CHI Conference on Human Factors in Computing Systems Proceedings (CHI 2019), May 4-9, 2019, Glasgow, Scotland UK. ACM, New York, NY, USA, 18 pages. https://doi.org/ $10.1145 / 3290605.3300361$

\section{INTRODUCTION}

Smartphones and laptops give their users access to an astonishing range of tasks anywhere, anytime. While this provides innumerable benefits, a growing amount of public discussion and research attention focuses on a perhaps unexpected downside [7, 19, 62, 102, 108, 121, 187, 201]: Having immense amounts of functionality available instantly and permanently often makes it difficult for users to focus on their current task and avoid being overly distracted by notifications or habitual check-ins [48, 117, 181, 185]. This challenge is compounded by the business models of many tech companies, which incentivise design that nudges people into using services frequently and extensively in order to optimise advertising revenue (cf. the 'attention economy' [50, 56, 75, 201]).

In response, a recent movement in HCI has called for more research into intentional 'non-use' of information and communication technologies (ICTs) [19, 78, 158]. Initial work looked into why some users quit, or take breaks from Facebook [19], Twitter [159], or other social networking sites, and a substantial body of related research has now established 
that a majority of users feel conflicted about the time they spend with internet-connected digital technologies and struggle with effective self-control [8, 63, 93, 94, 101, 108, 148, 173].

Researchers within this space have started to design, implement and test novel tools for supporting self-control over device use, using interventions such as gamification and social sharing of total time spent on one's smartphone (with rewards for reducing use) [94] or visualisation of laptop use [195]. Meanwhile, an entire market niche has appeared on the Android and Apple app stores, as well as on browser extension 'web stores', wherein hundreds upon hundreds of apps and extensions cater to people struggling with selfcontrol over device use, and provide interventions claimed to help users. Some of these 'digital self-control tools' - such as Forest [163], which gamifies self-control through growing of virtual trees - have gathered millions of users [69].

Yet, while the challenge of supporting self-control over use of always-connected digital devices has become widely discussed, our understanding of how best to approach it remains limited [cf. 45, 115, 116, 195]. While a growing number of studies have developed and evaluated novel design interventions, no systematic reviews have mapped design features in the hundreds of digital self-control tools that currently exist on the app and web stores [cf. 190]. Moreover, new design interventions developed by $\mathrm{HCI}$ researchers have mostly been informed by user interviews and intuitions of interface designers $[78,105,195]$, or by theories including cognitive load theory [37], Social Cognitive Theory [94] and nudge theory $[90,136]$. Meanwhile, the dual systems and valuebased models prominent in current cognitive neuroscience research on self-regulation ${ }^{1}[22,28,165,168,191,200]$ have yet to be applied [cf. 45, 145].

In this paper, we review 367 apps and browser extensions for digital self-control from the Google Play, Chrome Web, and Apple App stores, and identify common design features and strategies. As a theoretical lens to organise and evaluate these tools and provide a deeper understanding of the selfcontrol challenges they seek to address, we adapt and apply an integrative dual systems model drawn from established work within the cognitive neuroscience of self-regulation. Extending recent attempts at applying dual systems theory to digital behaviour change interventions [145], our formulation of the model incorporates recent research on the 'expected value of control' [167] as mediator of the strength of conscious self-control. This, we argue, demystifies the concept of self-control and helps clarify how specific design features may work to scaffold successful self-control.

\footnotetext{
${ }^{1}$ In cognitive psychology, Self-regulation is commonly used as an umbrella term for all regulatory processes in the service of goal-directed behaviour, including automatic habits, and self-control more restrictively about conscious, deliberate attempts at overriding immediate impulses that conflict with one's goals $[18,53,73,128]$.
}

\section{RELATED WORK}

\section{Evidence on Self-Control Challenges}

It has long been known that digital device use for some subset of users can become associated with severe breakdowns of self-regulation, causing distress or impaired functioning in important life domains [36]. Thus, for more than two decades, the concept of 'addiction' has been applied by some researchers to such instances, originally in terms of 'internet addiction' [204], and more recently 'social media' and 'Facebook addiction' [10, 113, 114, 156, 173], as well as 'cell phone' and 'smartphone addiction' [36, 157].

The current surge of public discussion around self-control struggles and unwanted distraction - as well as related initiatives by some of the tech giants $[11,67,68]$ - has a broader focus, namely daily self-control struggles experienced by most users [cf. 35, 199]. Here, an accumulating body of evidence suggests that a majority of people experience difficulties with self-control over device use [78, 93, 94, 101, 108, 195]. For example, in a survey by Ko et al. [94], a majority of smartphone users felt they were overusing their devices $(64 \%)$ and wanted to change their usage habits $(60 \%)$. The patterns respondents wished to change clustered around two themes: too frequent short usage, where incoming notifications or urges to e.g. check the news derailed focus from tasks they wished to complete; and excessive long usage, where e.g. habitually checking devices before bedtime 'sucked them in'. Most users also reported that their strategies for changing this behaviour most often failed, especially when relying on 'willpower', because good intentions to limit use tended to be overridden by momentary impulses [57, 94; cf. 80, 104, 152]. In addition to a growing amount of evidence from such surveys [78, 93], the wealth of articles and opinion pieces that in recent years have appeared on the topic in major news outlets, viral blog posts, and popular science books [e.g. 7, 62, 75, 91, 147, 201], as well as the fact that Apple, Google, and Facebook perceive a sufficiently large demand for features supporting user self-control to respond $[11,68,153]$, suggest that day-to-day struggles with self-regulation over device use are very common.

\section{Theory Applied in Related Research}

Digital Self-Control Tools. To understand the theory use in prior relevant $\mathrm{HCI}$ work, we identified $17 \mathrm{HCI}$ papers which have either built novel design intervention or evaluated existing interventions to support self-control over digital device use - see Table 1. For each of these, we examined which selfregulation theories were applied to guide tool development (if designing new interventions) and/or to evaluate effects on user behaviour and perceptions. These papers were a subset of a large body of literature on self-control in relation to digital device use, spanning psychology, neuroscience, 
behavioural economics, philosophy, and HCI, continuously collected over a period of two years $(500+$ papers altogether). While the literature included here aimed at comprehensively summarising current work in this area of $\mathrm{HCI}$, we note that they were not collected through a formal systematic review process.

In 7 out of 17 papers, no underlying self-regulation theory was specified, with tool development and/or assessment informed only by user-centered design methods such as surveys and interviews with target users and/or design experts. The 10 remaining papers all referred to distinct theoretical models from psychology (Social Cognitive Theory, classical conditioning, strength model of self-control), cognitive neuroscience (attentional resource theory, cognitive load theory, multitasking and inhibitory brain function), (behavioural) economics (nudge theory, framing effects, rational choice), behaviour change, and addiction research. For the purposes of the present paper, we note that none of the papers reviewed relied on dual systems models of self-regulation [cf. $45,145]$.

Digital Behaviour Change Interventions. A large body of HCI work exists on how digital tools can assist behaviour change in general [38, 59, 87, 103, 160, 203]. A main focus within such research on 'Digital Behaviour Change Interventions' (DBCIs, [145]) is health, for example in relation to how digital interventions may help users exercise more [38], quit smoking [1,76], eat more healthily [43, 137], cope with stress [65, 95], or manage chronic conditions [193].

Since digital self-control tools can be seen as a subset of DBCIs, understanding how self-regulation theory has been applied within this research area is relevant for the present paper. One recent review of 85 DBCI studies [140] found the Transtheoretical Model (or Stages of Change) [151] to be the most commonly referenced (13/85 papers), followed by Goal Setting Theory [106] (5/85) and Social Conformity Theory $[13,58](3 / 85) .60 \%(51 / 85)$ did not specify any theoretical basis [cf. 160,196], and none specified dual systems theory [cf. 145]. The review also found that among studies which did specify underlying theories, most only mentioned them without explaining how the theoretical constructs informed the design and/or evaluation of actual intervention components [140].

Another recent comprehensive review [145] noted that most theories applied in DBCI studies assume a rational, deliberative process as a key determinant of behaviour (e.g. the Transtheoretical Model [151] or the Theory of Planned Behaviour [6]). The authors further argued (after extensive review and discussion) that dual systems theory could be well placed to guide DBCIs research focusing on long-term behaviour change through breaking and forming habitual behaviour [145, 178, 200; cf. 194].

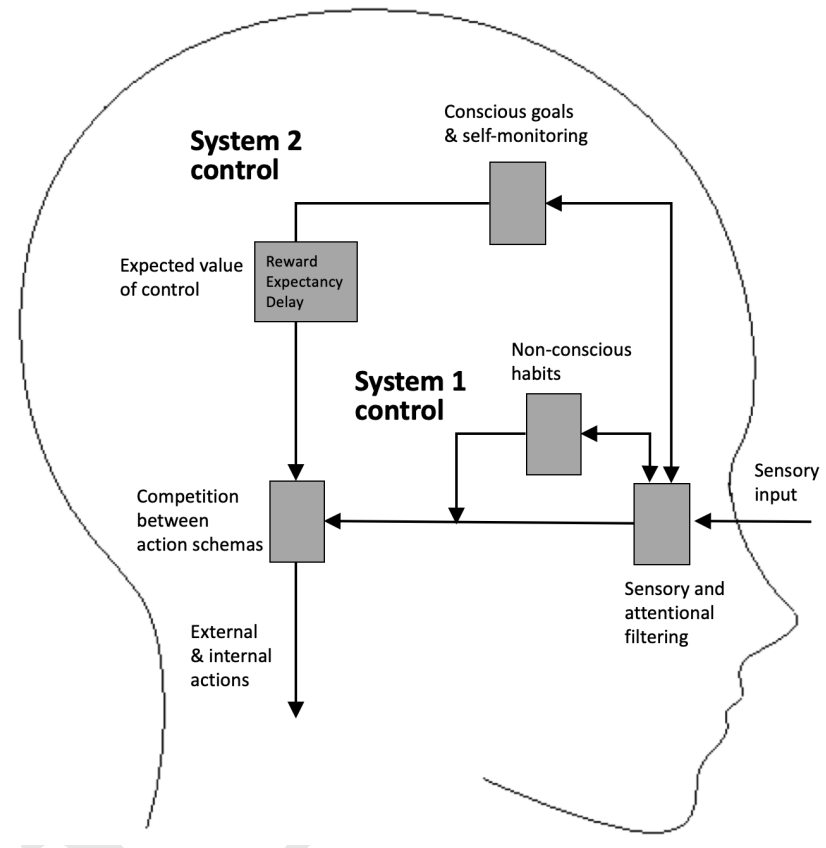

Figure 1: An extended dual systems model of self-regulation, developed from Shea et al. [165] and Norman \& Shallice [134]. System 1 control is rapid and non-conscious, whereas System 2 control is slower, conscious, and capacity-limited. The strength of System 2 control is mediated by the expected value of control.

\section{AN INTEGRATIVE DUAL SYSTEMS APPROACH TO DIGITAL SELF-CONTROL}

In the rest of the paper, we draw on dual systems theory and argue how it can be used to systematise and classify digital self-control tools. We start by outlining the basics of the underlying psychological research. In doing so, we extend current applications of dual system theories in DBCIs $[2,45,145,146]$ with the concept of 'expected value of control', which the neuroscience literature considers central in explaining why success at self-control fluctuates over time and with emotional state [28, 77, 82, 156, 167, 186]. An overview of the resulting model is shown in Figure 1.

Subsequently, we review current digital self-control tools on the Chrome Web, Google Play, and Apple App stores, and apply the model to organise and explain common design features, before pointing out gaps and opportunities for future work.

\section{System 1 and System 2}

The core of dual systems theories is a major distinction between swift, parallel and non-conscious 'System 1' processes, 
Table 1: Theories applied in existing work on digital self-control tools.

\begin{tabular}{|c|c|c|}
\hline Paper & Summary & Self-regulation theory \\
\hline $\begin{array}{l}\text { Lottridge et } \\
\text { al. } 2012[107]\end{array}$ & $\begin{array}{l}\text { Firefox extension which classifies URLs as work or non-work, then makes } \\
\text { non-work tabs less prominent and displays time spent }\end{array}$ & $\begin{array}{l}\text { Multitasking, inhibitory brain function } \\
\text { [64] }\end{array}$ \\
\hline $\begin{array}{l}\text { Löchtefeld et } \\
\text { al. } 2013[105]\end{array}$ & $\begin{array}{l}\text { AppDetox, an Android app which let users voluntarily create rules intended to } \\
\text { keep them from certain apps }\end{array}$ & None \\
\hline $\begin{array}{l}\text { Collins et al. } \\
2014[37]\end{array}$ & $\begin{array}{l}\text { RescueTime, a commercial Windows/Mac application which provides visualisa- } \\
\text { tions of how much time is spent in different applications }\end{array}$ & Cognitive Load theory [26] \\
\hline $\begin{array}{l}\text { Lee et al. } 2014 \\
{[100]}\end{array}$ & $\begin{array}{l}S A M S \text {, an Android app for tracking smartphone usage and setting time limits } \\
\text { for app use }\end{array}$ & $\begin{array}{l}\text { Relapse prevention model [70, 198], clini- } \\
\text { cal guidelines for internet addiction [205] }\end{array}$ \\
\hline $\begin{array}{l}\text { Ko et al. } 2015 \\
\text { [94] }\end{array}$ & $\begin{array}{l}\text { martphone app which let users set goals for limiting usage, then } \\
\text { rmance with friends and receive encouragement }\end{array}$ & Social Cognitive Theory [15] \\
\hline $\begin{array}{l}\text { Andone et al. } \\
2016 \text { [9] }\end{array}$ & $\begin{array}{l}\text { Menthal, a smartphone app displaying the 'MScore', a single number summaris- } \\
\text { ing overall phone usage, as well as a series of main usage measures }\end{array}$ & None \\
\hline $\begin{array}{l}\text { Hiniker et al. } \\
2016[78]\end{array}$ & $\begin{array}{l}\text { MyTime, an Android app } \\
\text { was hit) plus a daily pron }\end{array}$ & None \\
\hline $\begin{array}{l}\text { Kim et al. } \\
2016[90]\end{array}$ & $\begin{array}{l}\text { TimeAware, an ambient Windows and Mac widget which presents time spent } \\
\text { in 'distracting' or 'productive' applications }\end{array}$ & Framing effects [118] \\
\hline Ko et al. 2016 & Lock n'LoL, a smartphone app which lets users as a gro & None \\
\hline$[93]$ & & \\
\hline $\begin{array}{l}\text { Ruan et al. } \\
2016[154]\end{array}$ & $\begin{array}{l}\text { PreventDark, an Android app which detects phone use in the dark and notifies } \\
\text { the user that they should put it away }\end{array}$ & None \\
\hline $\begin{array}{l}\text { Whittaker et } \\
\text { al. } 2016[195]\end{array}$ & $\begin{array}{l}\text { MeTime, a computer application providing a floating visualisation of time spent } \\
\text { in different applications within the last } 30 \text { mins }\end{array}$ & None \\
\hline $\begin{array}{l}\text { Kim et al. } \\
2017[88]\end{array}$ & $\begin{array}{l}\text { Let's FOCUS, an Android and iOS app letting users enter a 'virtual room' where } \\
\text { notifications and apps are blocked; links to location or time }\end{array}$ & None \\
\hline $\begin{array}{l}\text { Kim et al. } \\
2017[89]\end{array}$ & $\begin{array}{l}\text { PomodoLock, a PC and Android application plus Chrome extension which blocks } \\
\text { distracting apps and websites during } 25 \text { minute focus sessions }\end{array}$ & Strength model of self-control [18] \\
\hline $\begin{array}{l}\text { Marotta et al. } \\
2017[117]\end{array}$ & $\begin{array}{l}\text { Freedom, a commercial Windows/Mac/Android/iOS app which blocks access to } \\
\text { distracting parts of the web or the internet altogether }\end{array}$ & Rational choice, 'self-commitment' [31] \\
\hline $\begin{array}{l}\text { Kovacs et al. } \\
2018 \text { [97] }\end{array}$ & $\begin{array}{l}\text { HabitLab, a Chrome extension in which the user sets time limit goals for specific } \\
\text { sites, then tries a range of interventions to reach the goal }\end{array}$ & $\begin{array}{l}\text { Numerous, including goal setting theory } \\
\text { [106], operant conditioning [16], and self- } \\
\text { consistency theory [169] }\end{array}$ \\
\hline $\begin{array}{l}\text { Mark et al. } \\
2018[115]\end{array}$ & Freedom, d & Attentional resources [197], Big 5 [120] \\
\hline $\begin{array}{l}\text { Okeke et al. } \\
2018[136]\end{array}$ & $\begin{array}{l}\text { Android app nudging users to close Facebook when a usage limit has been hit, } \\
\text { using pulsing vibrations that stop when the user leaves the site }\end{array}$ & $\begin{array}{l}\text { Nudge theory [183], negative reinforce- } \\
\text { ment [84] }\end{array}$ \\
\hline
\end{tabular}

and slower, capacity-limited and conscious 'System 2' processes $[41,85,124,125,165,170,174] .^{2}$

According to this model, System 1 control is driven by environmental inputs and internal states along with cognitive pathways that map the current situation to well-learned habits or instinctive responses [125]. Behaviour driven by System 1 is often called 'automatic', as it allows tasks to be initiated or performed without conscious awareness and with little interference with other tasks [134]. Instinctive responses like scratching mosquito bites, or frequent patterns of digital device use like picking up one's smartphone to

\footnotetext{
${ }^{2}$ The related 'Nudge theory' [183] draws upon dual systems theories to describe how to exploit System 1 and sometimes System 2 processes to guide people towards a desired action [cf. 2].
}

check for notifications, can happen automatically via System 1 control [cf. 28, 141, 189].

System 2 control is driven by goals, intentions, and rules held in conscious working memory $[14,124]$. From these central representations, signals are sent to cognitive systems that process sensory input, memory retrieval, emotional processing, and behavioural output, to guide responses accordingly [125]. System 2 control is necessary when a goal requires planning or decision-making, or overcoming of habitual responses or temptations [134], for example if one has a goal of not scratching mosquito bites or not checking a smartphone notification. 


\section{Action schema competition}

From a neuroscience perspective, the building blocks of behaviour are hierarchical action schemas, that is, control units for partially ordered sequences of action that achieve some goal when performed in the appropriate order $[40,134]$. Action schemas exist at varying levels of complexity, from simple single-action motor schemas for grasping and twisting, to higher level schemas for e.g. preparing tea by filling and boiling a kettle $[29,164]$. The schemas compete for control over behaviour in a 'competitive selection' process in which schemas act like nodes in a network, each with a continuous activation value [164], and the 'winner' is the node with the strongest activation [92,145]. Schema nodes are activated by a number of sources, including sensory input via System 1 processes ('bottom-up'), 'parental' influence from superordinate schemas in the hierarchy, and top-down influence from System 2 control $[40,164]$.

\section{Self-regulation and self-control}

Following others, we use self-regulation as an umbrella term for regulatory processes in the service of goal-directed behaviour, including automatic System 1 habits, and self-control more restrictively for conscious and deliberate System 2 control in situations where immediate impulses conflict with enduringly valued goals $[18,53,73,128]$. For example, if a person wishes to be less distracted by her smartphone in social situations, and through repetition has acquired a habit of turning the phone face-down to the point that she now does it without conscious attention, this counts as self-regulation. If in a given moment she feels an urge to flip it over and check for notifications, but consciously suppresses this impulse and does not act on it, this counts as self-control.

Self-regulation and self-control are mediated by feedback functions for monitoring the state of oneself and the environment, comparing this state to goals and standards [cf. 165], and acting to modify the situation accordingly $[17,34,81$; cf. cybernetic models of behaviour control, 33, 149].

\section{Attentional filtering}

For goals, rules, or intentions to guide System 2 control, they must first enter working memory $[14,124]$. Entry of information from the external world, internal states, or memory stores into working memory is itself a competitive process, in which the signals with the highest activation values are given access by attentional filters [39, 92, 125].

Automatic bottom-up filters look out for stimulus properties that are likely to be important, either through innate sensitivities (e.g. sudden or looming noises) or learned associations (e.g. a smartphone notification) and boost their signal strength [92]. In this way, some stimuli may evoke a response strong enough to gain automatic access to working memory even while we have our minds on other things $[55,83]$. For example, clickbait uses headlines and imagery with properties that makes bottom-up attention filters put its information on a fast track to conscious working memory or trigger click-throughs via System 1 control [cf. 27].

Conscious System 2 control can also direct attention towards particular internal or external sources of information (e.g. focusing on a distorted voice in one's cellphone on a crowded train), which increases the signal strength of those sources and makes the information they carry more likely to enter working memory $[42,92,132,171]$.

\section{Self-control limitations and the Expected Value of Control}

A central puzzle is why people often fail to act in accordance with their own valued goals, even when they are aware of the mismatch [54]. According to current research on cognitive control, the two key factors to answer this question are (i) limitations on System 2 control in relation to capacity; and (ii) fluctuations due to emotional state and fatigue [28].

Capacity limitations. The amount of information that can be held in working memory and guide System 2 control, is limited (classically 'seven, plus or minus two' chunks of meaningful information [44, 126]). Therefore, self-control can fail if the relevant goals are simply not represented in working memory at the time of action [96]. This is one explanation for why people often struggle to manage use of e.g. Facebook or email - one opens the application with a particular goal in mind, but information from the news feed or inbox hijacks attention and crowds out the initial goal.

Fluctuations due to emotional state and fatigue. System 2 control often suffers from fatigue effects if exerted continuously $[25,49,73,79]$ and also fluctuates with emotional state [186]. For example, negative mood is a strong predictor of relapse of behaviour people attempt to avoid [77, 127, 186], and studies of Facebook use have found that users are worse at regulating the time they spend on the platform when in a bad mood [156, cf. 130].

The emerging consensus explanation of these fluctuations is that the strength of System 2 control is mediated by a costbenefit analysis of the outcome that exercising self-control might bring about [28] i.e., the expected value of control (EVC) $[167]^{3}$. The research suggests that EVC is influenced by at least three major factors:

\footnotetext{
${ }^{3}$ The alternative and influential 'ego-depletion' explanation [18] suggests that System 2 control relies on a limited resource that could be depleted, and which has a 'refraction period' before optimal self-control can again be exercised [73]. This model has intuitive appeal but has not withstood scrutiny [109], as original studies have failed to replicate [72, 202], depletion effects have shown to be reversible by increasing the rewards for sustained
} 
First, EVC increases the more reward people perceive they could obtain (or the greater the loss that could be avoided) through successful self-control [3, 28, 142, 143]. To illustrate, consider 'phone stack', in which a group dine at a restaurant and begin by stacking up their phones on the table. The first person to take out his phone from the stack to check it, has to pay the entire bill $[71,184]$. This game aids self-control over device use by introducing a financial (and reputational) cost which adjusts the overall expected value of control (cf. also Ko et al.'s tool NUGU [94]).

Second, EVC increases the greater expectancy, or perceived likelihood, that one will be able to bring a given outcome about through self-control [23, 180, 192; cf. 'selfefficacy' in Social Cognitive Theory, 15]. In the phone stack example, people may try harder to suppress an urge to check their phone, the more confidence they have in their ability to control themselves in the first place.

Third, EVC decreases the longer the delay before the outcome that self-control might bring about (cf. 'future discounting' $[4,5,12,46,60,119,135])$. In phone stack, we should expect people to be worse at suppressing an impulse to check their phone if the rules were changed so that the loser would pay the bill for a meal in 10 years' time.

\section{A practical example}

As an illustration of the model and the benefits of including EVC, consider a student who opens his laptop to work on an essay. However, he instead checks Facebook and spends an inordinate amount of time scrolling the news feed, experiencing feelings of regret having done so when he finally returns to the essay. This is not the first time it happened, even though his reflective goal is always to do solid work on the essay as the first thing, and to only allow himself to check Facebook briefly during breaks.

Our model suggests that we think about this situation in terms of the perceptual cues in the context, automatic System 1 behaviour control, System 2's consciously held goals and self-monitoring, and System 2's expected value of control:

If the student normally checks Facebook when opening his laptop, this context may trigger a habitual check-in via System 1 control. His goal of working first thing might be present in his working memory, but he might fail to override his checking habit due to his expected value of control being low. This might be because he did not get any reward from inhibiting the impulse to check Facebook; because he had little confidence in his own ability to suppress this urge (low expectancy); or because the rewards from working on his essay were delayed because it was only due in two months. Alternatively, his goal of working on the essay first thing

performance [73, 133], and the purported physical resource underlying the effect failed to be discovered $[99,129]$. might not be present in his working memory, in which case no System 2 control was initiated to override the checking habit.

After having opened Facebook, he might remember that he should be working on the essay, but attention-grabbing content from the newsfeed enters his capacity-limited working memory and crowd out this goal, leading him to spend more time on Facebook than intended.

\section{A REVIEW AND ANALYSIS OF CURRENT DIGITAL SELF-CONTROL TOOLS}

To explore how this model may be useful in mapping digital self-control interventions, we conducted a systematic review and analysis of apps on the Google Play and Apple App stores, as well as browser extensions on the Chrome Web store. We identified apps and browser extensions described as helping users exercise self-control / avoid distraction / manage addiction in relation to digital device use, coded their design features, and mapped them to the components of our dual systems model ${ }^{4}$.

\section{Methods}

Initial Keyword Search and Data Clean Up. For the Google Play and Apple App store, we used pre-existing scripts [138, 139] to download search results for the terms 'distraction', 'smartphone distraction', 'addiction', 'smartphone addiction', 'motivation', 'smartphone motivation', 'self-control' and 'smartphone self-control'. For the Chrome Web store, we developed our own scraper [172] and downloaded search results for the same key terms, but with the prefix 'smartphone' changed to 'laptop' as well as 'internet' (e.g. 'laptop distraction' and 'internet distraction'). We separately scraped apps and extensions on the US and UK stores, between 22nd and 27th August 2018. After excluding duplicate results returned by multiple search terms and/or by both the US and UK stores, this resulted in 4890 distinct apps and extensions (1571 from Google Play, 2341 from the App Store, and 978 from the Chrome Web store).

Identifying Potentially Relevant Apps and Extensions. Following similar reviews [166, 179], we then manually screened the titles and short descriptions (if available; otherwise the first paragraphs of the full description). We included apps and extensions explicitly designed to help people self-regulate their digital device use, while excluding tools intended for general productivity, self-regulation in other domains than digital device use, or which were not available in English (for detailed exclusion criteria, see osf.io/zyj4h).

\footnotetext{
${ }^{4}$ Data and scripts for reproducing our analyses (as well as this paper written in R Markdown [cf. 111]) are available on osf.io/zyj4h.
} 


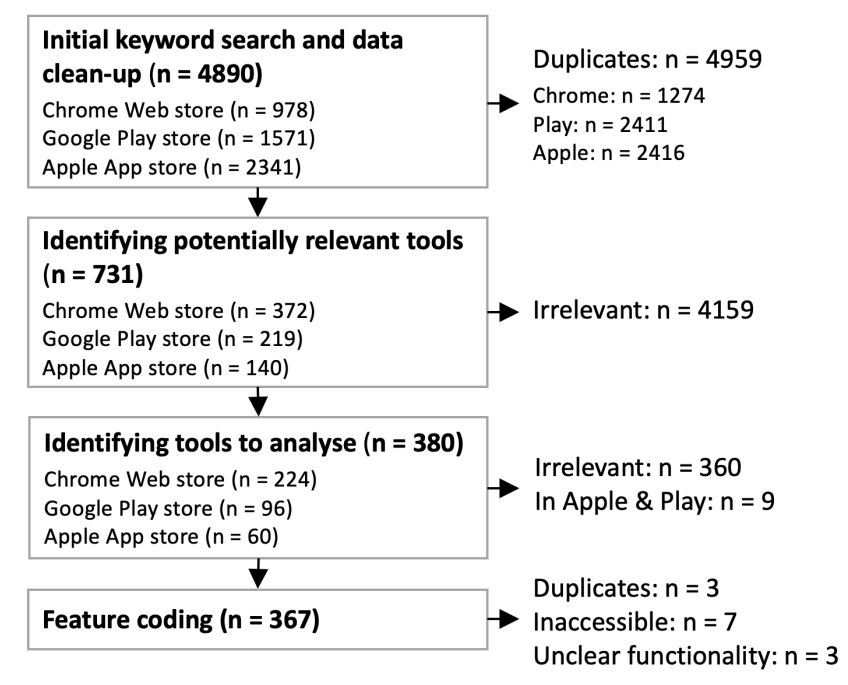

Figure 2: Flowchart of the search and exclusion/inclusion procedure

This resulted in 731 potentially relevant apps and extensions (219 from Google Play, 140 from the App Store, and 372 from the Chrome Web store).

Identifying Apps and Extensions to Analyse. We reviewed the remaining tools in more detail by reading their full descriptions. If it remained unclear whether an app or extension should be excluded, we also reviewed its screenshots. If an app existed in both the Apple App store and the Google Play store, we dropped the version from the Apple App store. ${ }^{5}$

After this step, we were left with 380 apps and extensions to analyse (96 from Google Play, 60 from the App Store, and 224 from the Chrome Web store).

Feature coding. Following similar reviews, we coded functionality based on the descriptions, screenshots, and videos available on a tool's store page [cf. 166, 177-179]. We iteratively developed a coding sheet of feature categories [cf. $20,140]$, with the prior expectation that the relevant features would be usefully classified as subcategories of the main feature clusters 'block/removal', 'self-tracking', 'goal advancement' and 'reward/punishment' (drawing on our previous work in this area [110]).

Initially, three of the authors independently reviewed and classified features in 10 apps and 10 browser extensions (for a total of 30 unique apps and 30 unique browser extensions)

\footnotetext{
${ }^{5}$ Apple's iOS places more restrictions on developer access to operating system permissions than does Google's Android, with the consequence that the iOS version of a digital self-control app is often much more limited than its Android counterpart [131]. Because the purpose of our review was to investigate which areas of the design space these tools have been explored (rather than differences between iOS and Android ecosystems per se), we excluded the iOS version when an app was available in both stores.
}

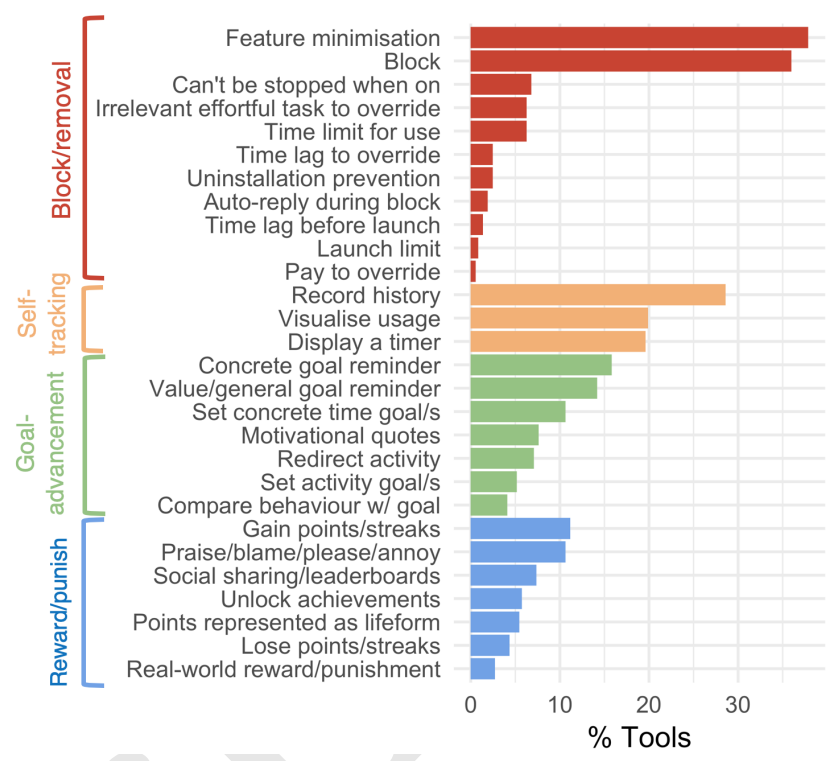

Figure 3: Functionality of digital self-control tools $(\mathbf{N}=367)$

before comparing and discussing the feature categories identified and create the first iteration of the coding sheet. Using this coding sheet, two authors independently reviewed 60 additional apps and browser extensions each and a third author these 120 tools, as well as all remaining. After comparing and discussing the results, a final codebook was developed, on the basis of which the first author revisited and recoded the features in all tools. In addition to the granular feature coding, we noted which main feature cluster(s) represented a tool's 'core' design, according to the guideline that $25 \%$ or more of the tool's functionality related to that cluster (a single tool could belong to multiple clusters). ${ }^{6}$

During the coding process, we excluded a further 13 tools - 3 duplicates, e.g. where 'pro' and 'lite' versions had no difference in described functionality, 7 that had become inaccessible after the initial search, and 3 that lacked sufficiently well-described functionality to be coded. This left 367 tools in the final dataset.

\section{Results}

Feature prevalence. A summary of the prevalence of features is shown in Figure 3. The most frequent feature cluster related to blocking or removing distractions, some variation of which was present in $74 \%$ of tools. $44 \%$ (163) enabled the user to put obstacles in the way of distracting functionality by either blocking access entirely (132 tools), or by setting limits on how much time could be spent ( 23 tools) or how many times distracting functionality could be launched (3 tools) before being blocked, or by adding a time lag before

${ }^{6}$ For further detail, see osf.io/zyj4h. 
distracting functionality would load (5 tools). $14 \%$ of tools (50) also added friction if the user attempted to remove the blocking, including disallowing a blocking session from being stopped (25 tools), requiring the user to first complete an irrelevant effortful task or type in a password (23 tools), tinkering with administrator permissions to prevent the tool from being uninstalled ( 9 tools), or adding a time lag before the user could override blocking or change settings ( 9 tools). For example, the Focusly Chrome extension [188] blocks sites on a blacklist; if the user wishes to override the blocking, she must type in correctly a series of 46 arrow keys (e.g. $\rightarrow \uparrow \downarrow \rightarrow \leftarrow \rightarrow \ldots)$ correctly to enter the blocked site.

Rather than blocking content per se, an alternative approach, taken by $38 \%$ of tools (139), was to reduce the user's exposure to distracting options in the first place. This approach was dominated by browser extensions (121 of these tools were from the Chrome Web store) typically in the form of removing elements from specific sites (67 tools; e.g. removing newsfeeds from social media sites or hiding an email inbox). The sites most frequently targeted were Facebook (26 tools), YouTube (17), Twitter (11) and Gmail (7). Also popular were general 'reader' extensions for removing distracting content when browsing the web (27 tools) or when opening new tabs (24). Other notable examples were 'minimalwriting' tools (22 tools) which remove functionality irrelevant to, or distracting from, the task of writing. Finally, a few Android apps (4 tools) limited the amount of functionality available on devices' home screen.

The second most prevalent feature cluster related to selftracking, some variation of which was present in $38 \%$ of tools (139). Out of these, 105 tools recorded the user's history, 73 provided visualisations of the captured data, and 72 displayed a timer or countdown. In 42 tools, the self-tracking features included focused on the time during which the user managed to not use their digital devices, such as the iOS app Checkout of your phone [162].

The third most prevalent feature cluster related to goal advancement, some variation of which was present in $35 \%$ of tools (130). 58 tools implemented reminders of a concrete time goal or task the user tried to complete (e.g. displaying pop-ups when a set amount of time has been spent on a distracting site or by replacing the content of newsfeeds or new tabs with todo-lists) and 52 tools provided reminders of more general goals or personal values (e.g. in the form of motivational quotes). 58 tools asked the user to set explicit goals, either for how much time they wanted to spend using their devices in total or in specific apps or websites (39 tools), or for the tasks they wanted to focus on during use (19 tools). 15 tools allowed the user to compare their actual behaviour against the goals they set.
The fourth most prevalent feature cluster, present in $22 \%$ of tools (80), related to reward/punishment, i.e. providing some rewards or punishments for the way in which a device is used. Some of these features were gamification interventions such as collecting points/streaks (41 tools), leaderboards or social sharing (27), or unlocking of achievements (21). In 20 tools, points were represented as some lifeform (e.g. an animated goat or a growing tree) which might be harmed if the user spent too much time on certain websites or used their phone during specific times. 10 tools added real-world rewards or punishments, e.g. making the user lose money if they spend more than 1 hour on Facebook in a day (Timewaste Timer [150]), allowing virtual points to be exchanged to free coffee or shopping discounts (MILK [123]) or even let the user administer herself electrical shocks when accessing blacklisted websites (!) (PAVLOK [144]).

Finally, 35\% of tools (129) gave the user control over what counted as 'distraction', e.g. by letting the user customise which apps or which websites to restrict access to. Among tools implementing blocking functionality, 101 tools implemented blacklists (i.e. blocking specific apps or sites, allowing everything else), while 22 tools implemented whitelists (i.e. allowing only specified apps or sites while blocking everything else).

Feature combinations. $65 \%$ of tools had only one feature cluster at the core of their design, the most frequent of which was blocking/removing distractions (53\%). 32\% (117 tools) combined two main feature clusters, most frequently block/removal in combination with goal-advancement (40 tools; e.g. replacing the Facebook newsfeed with a todo list, or replacing distracting websites with a reminder of the task to be achieved) or self-tracking in combination with reward/punishment features (30 tools; e.g. a gamified pomodoro timer in which an animated creature dies if the user leaves the app before the timer runs out). Block/removal core designs were also commonly combined with self-tracking (24 tools; e.g. blocking distracting websites while a timer counts down, or recording and displaying how many times during a block session the user tried to access blacklisted apps). Only two tools (Flipd [61] and HabitLab [176]) combined all four feature clusters in their core design, with the Chrome extension HabitLab (developed by the Stanford HCI Group) cycling through different types of interventions to learn which best help the user align internet use with their stated goals [cf. 97].

Store comparison. Figure 4 summarises the prevalence of features, comparing the three stores. The differences between the stores appear to mirror the granularity of system control available to developers: Feature minimisation, in the form of removing particular aspects of the user interface, is common in browser extensions, presumably because developers here 


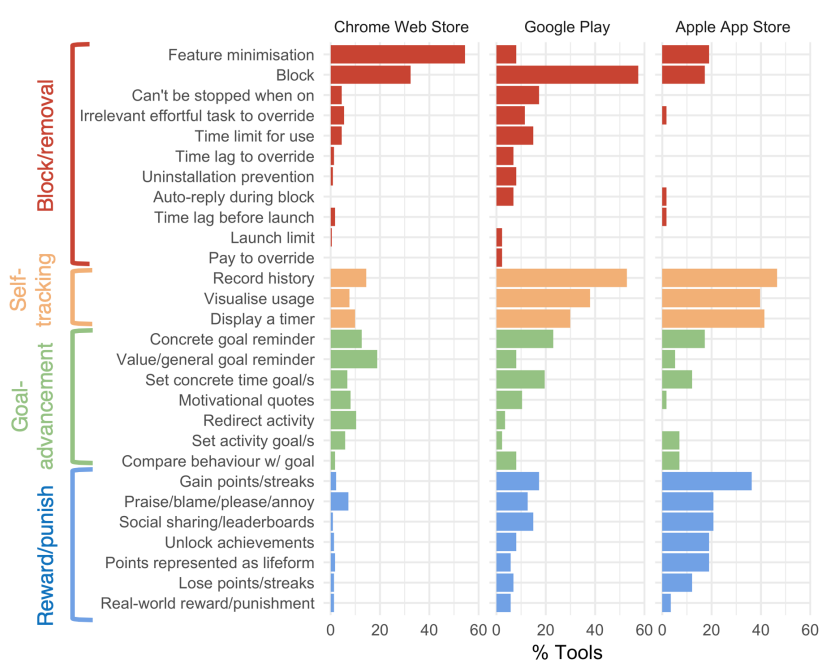

Figure 4: Functionality of digital self-control tools on Chrome Web $(n=223)$, Google Play $(n=86)$ and Apple App Store $(\mathbf{n}=\mathbf{5 8})$

can wield precise control over the elements displayed on HTML pages by injecting client-side CSS and JavaScript. On mobile devices, however, developers have little control over how another app is displayed, leaving blocking or restricting access as the only viable strategies. The differences between the Android and iOS ecosystems are apparent, as the permissions necessary to implement e.g. scheduled blocking of apps are not available to iOS developers. These differences across stores suggest that if mobile operating systems granted more permissions (as some developers of popular anti-distraction tools have petitioned Apple to do [51]), developers would respond by creating tools that offer more granular control of the mobile user interface, similar to those that already exist for the Chrome web browser.

Mapping identified tool features to theory. Figure 4 shows a matrix of how the design features corresponds to the main components of the integrative dual systems model, in terms of the cognitive components they have the most immediate potential to influence: Non-conscious habits are influenced by features that block the targets of habitual action or the user interface elements that trigger them, thereby preventing unwanted habits from being activated. Non-conscious habits are also influenced by features which enforce limits on daily use, or redirect user activity, thereby scaffolding formation of new habits. Conscious goals \& self-monitoring is influenced by explicit goal setting and reminders, as well as by timing, recording, and visualising usage and comparing it with one's goals. The reward component of the expected value of control is influenced by reward/punishment features that add incentives for exercising self-control, as well as by value/general

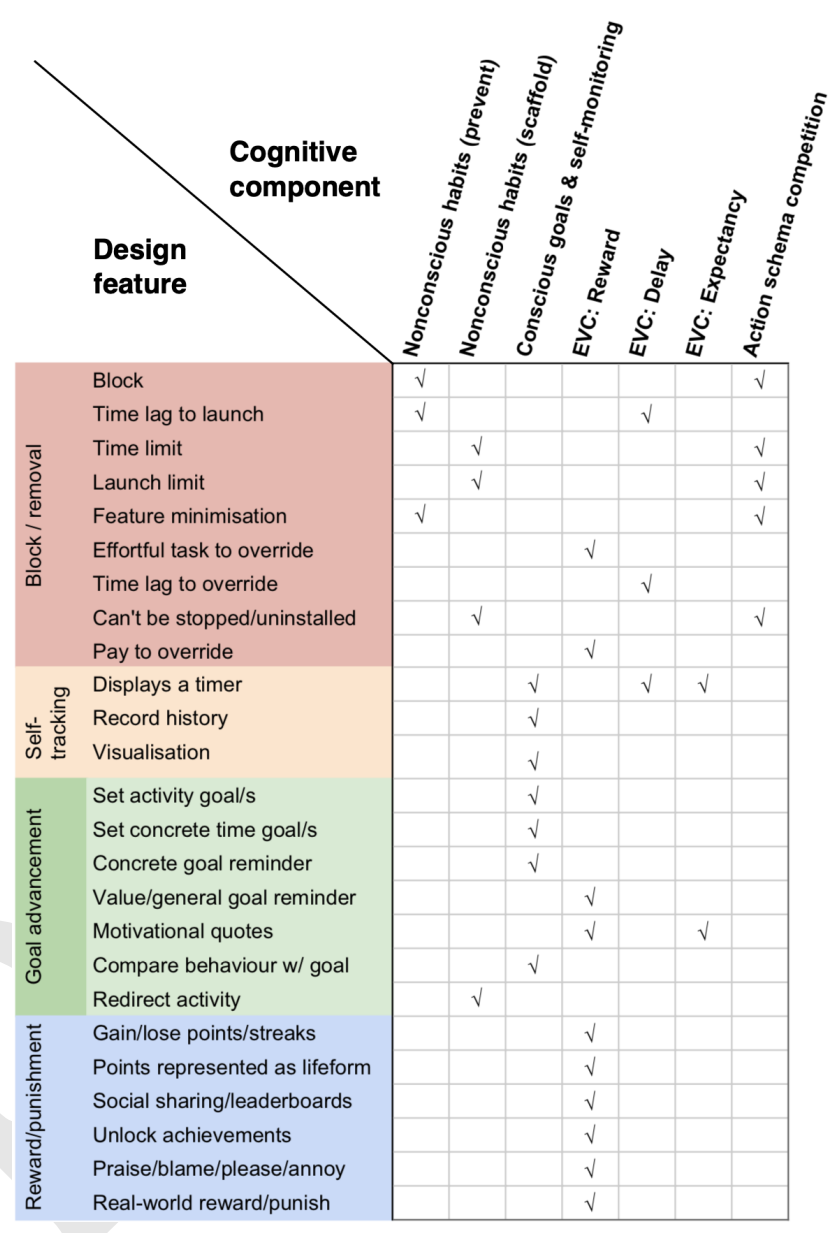

Figure 5: Mapping of design features to an integrative dual systems model of self-regulation

goal reminders and motivational quotes which encourage the user to reappraise the value of immediate device use in light of what matters in their life; the delay component is influenced by time lags or timers; and expectancy is similarly influenced by timers ('I should be able to manage to control myself for just 20 minutes!') as well as motivational quotes. Finally, the action schema competition, which ultimately controls behaviour, is most directly affected by blocking/removal functionality that hinders unwanted responses from being expressed by simply making them unavailable.

Given this mapping, the percentages of tools in which at least one design feature maps to a given cognitive component is shown in Figure 6. Similarly to DBCI reviews $[145,178]$, we find the lowest prevalence of features that scaffold formation of non-conscious habits (18\%), followed by features that influence the delay component of the expected value of control (23\%). The current landscape of digital self-control tools is dominated by features which prevent activation of unwanted 


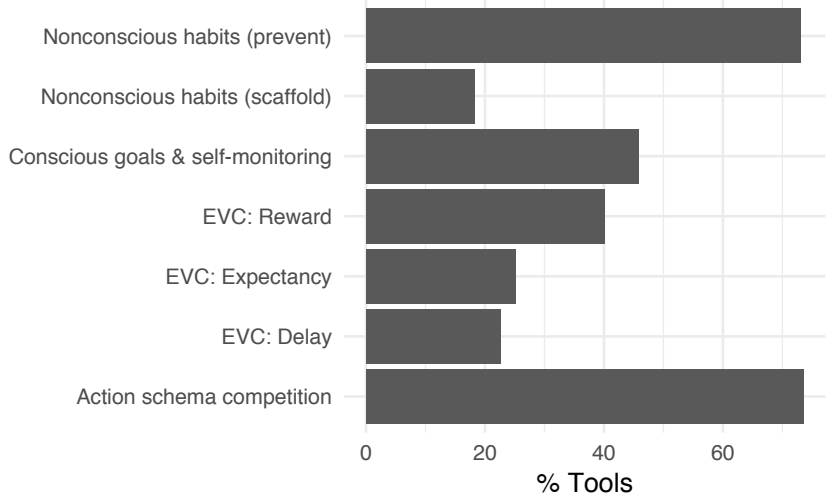

Figure 6: Percentage of tools which include at least one design feature targeting a given cognitive component of the dual systems model of self-regulation.

non-conscious habits (73\%) and thereby stop undesirable responses from winning out in action schema competition by making them unavailable.

\section{DISCUSSION}

This study set out to map the landspace of current digital selfcontrol tools and relate them to an integrative dual systems model of self-regulation. Our review of 367 apps and browser extensions found that blocking distractions or removing user interface features were the most common approaches to digital self-control. Grouping design features into clusters, the prevalence ranking was block/removal > self-tracking > goal advancement $>$ reward/punishment. Out of these, $65 \%$ of tools focused on only one cluster in their core design; and most others $(32 \%)$ on two. The frequencies of design features differed between the Chrome Web Store, Play Store, and Apple App store, which likely reflects differences in developer permissions. When mapping design features to our dual systems model, the least commonly targeted cognitive component was unconscious habit scaffolding, followed by the delay and expectancy elements of the expected value of control.

We now turn to discuss how these empirical observations can inform future research by pointing to: i) widely used and/or theoretically interesting design features in current digital self-control tools that are underexplored in HCI research; ii) feature gaps identified by our application of the dual systems model, showing neglected areas that could be relevant to researchers and designers, and iii) how the model may be used directly to guide research and intervention design. We then outline limitations and future work.

\section{Research opportunities prompted by widely used or theoretically interesting design features}

The market for digital self-control effectively amounts to hundreds of natural experiments in supporting self-control, meaning that successful tools may reveal design approaches with wider applicability. These approaches present low-hanging fruit for research studies, especially as many are so far lacking evaluation in terms of their efficacy and the transferability of their underlying design mechanisms. As an example, we highlight three such instances:

Responsibility for a virtual creature: Forest [163] ties device use to the well-being of a virtual tree. Numerous variations and clones of this approach exist among the tools reviewed, but Forest is the most popular with over 5 million users on Android alone. It presents a novel use of 'virtual pets' that requires the user to abstain from action (resist using their phone) rather than take action to 'feed' the pet, and is a seemingly successful example of influencing the reward component of expected value of control.

Redirection of activity: Timewarp [182] reroutes the user to a website aligned with their productivity goals when navigating to a distracting site (e.g. from Reddit to Trello), and numerous tools implement similar functionality. Such apps seem to be automating 'implementation intentions' (if-when rules for linking a context to a desired response [66]), an intervention which digital behaviour change researchers have highlighted as a promising way to scaffold transfer of conscious System 2 goals to automatic System 1 habits $[145,178]$.

Friction to override past preference: A significant number of tools not only allow the user to restrict access to digital distractions, but also add a second layer of commitment, e.g. by making blocking difficult to override, as in the browser extension Focusly [188], which requires a laborious combination of keystrokes to be turned off. This raises important design and ethical questions about how far a digital tool should go to hold users accountable for their past preferences [cf. $31,112]$.

\section{Gaps identified by the dual systems model}

By applying our model, we also identified three cognitive mechanisms that appear underexplored by current digital self-control tools. We argue that focusing on these mechanisms could lead to new powerful models for digital selfcontrol:

Scaffolding habits. Similar to the situation in general DBCIs [cf. 145, 178], the least frequently targeted cognitive component relates to scaffolding of new, desirable unconscious habits (as opposed to preventing undesired ones from being triggered via blocking or feature removal). Habit formation is crucial for long-time behaviour change, and in the context 
of DBCIs, Pinder et al. [145] suggested implementation intentions and automation of self-control as good candidate strategies for habit targeting. We note that some such design interventions are already being explored amongst current digital self-control tools: Apart from the tools mentioned above that redirect activity, we highlight that four tools allow blocking functionality to be linked to the user's location (e.g. AppBlock [175] and Bashful [155]). We expect this to be a powerful way of automatically triggering a target behaviour in a desired context.

Delay. The delay component of expected value of control is also less commonly targeted: the number of tools including functionality targeting delay drops to $4 \%$ if we exclude the display of a timer (which raises time awareness rather than affecting actual delays). This is surprising from a theoretical perspective, because the effects on behaviour of sensitivity to delay are strong, reliable, and-at least to behavioural economists-at the core of self-control difficulties $[12,52]$. Even if rewards introduced by gamification features may have the side effect of reducing delay before self-control is rewarded, it remains surprising that only two of 367 reviewed tools directly focused on using delays to scaffold successful self-control (Space [30] increases launch times for distracting apps on iOS; Pipe Clogger [47] does the same for websites). As previous research has found people to be especially sensitive to delays in online contexts [98], we expect interventions that leverage delays to scaffold self-control in digital environments to be highly effective.

Expectancy. The expectancy component (i.e. how likely a user think it is that she will be able to reach her goal through self-control exertion) was also less frequently targeted, and mainly through timers limiting the duration where the user tried to exert self-control. Given the crucial role of self-efficacy in Bandura's influential work on self-regulation [15], this may also represent an important underexplored area. One interesting approach to explore is found in Wormhole Escaper [21] which lets the user administer words of encouragement to themselves when they manage to suppress an urge to visit a distracting website. In so far as this is effective, it may be by boosting the user's confidence in their ability to exert self-control.

\section{Using the model directly to guide intervention research and design}

The abstracted nature of the model enables it to be utilised on different levels of analysis to inspire new avenues for research as well as drive specific design:

For researchers, the model may be used to organise existing work on design interventions by the cognitive components targeted, as well as a roadmap for future studies that focus on different components of the self-regulatory system. Whereas many other theories and frameworks are on offer for this purpose, one advantage of the dual systems model is that it provides HCI researchers with clear connections to wider psychological research on basic mechanisms of self-regulation, which can be utilised in design.

As such, the model may be used as a starting point for design consideration that is aligned with the cognitive mechanisms involved in self-regulation; its components can be readily expanded if inspiration from more theoretical details and predictions is required. For example, the 'reward' component readily expands into more specific models explaining the types of stimuli that may be processed as rewards; how timing of rewards impact their influence; how the impact of gains differ from losses; and so on [24, 32, 86, 161].

Two recent examples in HCI research illustrate such possible use of psychological theory in the design process: In the design and development of TimeAware, Kim et al. were guided by work on differential sensitivity to gains vs losses, and found that their visualisation tool more effectively supported productivity when displaying time spent engaging with distracting rather than productive activities [90]. Similarly, based on dual systems theory, Adams et al. [2] trialed ways of applying visual and auditory perception biases in design interventions to influence food choice and voice pitch. We hope our model may inspire designs that are similarly informed by psychological theory.

\section{Limitations and future work}

Our review has some limitations. First, due to space restrictions, and because information about numbers of users are not available on the Apple App Store, our tool analysis has focused on functionality analysis, while leaving consideration of numbers of installs or content of user reviews to future work. We note that this is similar to the approach taken by other reviews in related areas [177, 178].

Second, the integrative dual systems model we have applied points to directions of future research, but its highlevel formulation leaves its cognitive design space underspecified. How precisely one should be able to anchor details of specific interventions directly in causal theories is a point of longstanding debate $[6,74,122]$. A main benefit of dual systems theory, however, is that while concise, it remains directly grounded in well-established basic research on self-regulation. As mentioned above, this means that each component of the model has substantial literature behind it, so that more detailed specifications and predictions can be found in lower-level theories on demand.

Turning to the future, self-control in relation to digital device use involves unique challenges and opportunities compared to general behaviour change research. On the one hand, portable, powerful, internet-connected devices present an unprecedented self-regulation challenge: Never before have 
so many behavioural options, information about nearly everything, engaging games, and communication with friends, family, and strangers, been instantly available. On the other hand, this very challenge presents a unique research opportunity. Precisely because digital devices afford so much functionality, they allow us to test design interventions with greater precision, flexibility, and dramatically lower cost than changing the physical environment. Moreover, context detection, a constant challenge in DBCI research for administering meaningful and well-timed interventions [145], is more manageable in relation to device use, because a large amount of relevant activity can be easily measured.

The research on digital self-control tools should therefore be of wide interest as a test bed for interventions that optimise self-control in an environment where most factors can be changed at minimal cost.

\section{CONCLUSION}

The challenge of designing powerful, always-connected digital devices that support self-control over their use, is important to address. This paper contributes to such efforts on two levels: (i) by providing the first comprehensive functionality analysis of current apps and browser extensions for digital self-control on the Google Play, Chrome Web, and Apple App stores, and (ii) by applying a well-established model of self-regulation to evaluate their design features and provide a mechanistic understanding of the problem they address.

The future to hope for is one in which users develop beneficial habits of technology use and are resilient against predatorial nudging by clickbait advertisers and data harvesters. We hope our review of 367 apps and browser extensions representing natural experiments in designing for digital self-control, and our formulation of a dual systems model to understand them, will help us realise this future.

\section{REFERENCES}

[1] Lorien C. Abroms, Nalini Padmanabhan, Lalida Thaweethai, and Todd Phillips. 2011. iPhone apps for smoking cessation: A content analysis. American fournal of Preventive Medicine 40, 3 (2011), 279-285. https://doi.org/10.1016/j.amepre.2010.10.032

[2] Alexander T. Adams, Jean Costa, Malte F. Jung, and Tanzeem Choudhury. 2015. Mindless Computing: Designing Technologies to Subtly Influence Behavior. In Proceedings of the 2015 ACM International foint Conference on Pervasive and Ubiquitous Computing. ACM, 719-730. https://doi.org/10.1145/2750858.2805843

[3] R. Alison Adcock, Arul Thangavel, Susan Whitfield-Gabrieli, Brian Knutson, and John D.E. Gabrieli. 2006. Reward-Motivated Learning: Mesolimbic Activation Precedes Memory Formation. Neuron 50, 3 (2006), 507-517. https://doi.org/10.1016/j.neuron.2006.03.036

[4] G. Ainslie. 2001. Breakdown of Will. Cambridge University Press.

[5] G. Ainslie. 2010. Procrastination: The Basic Impulse. In The Thief of Time: Philosophical Essays on Procrastination, Andreou Chrisoula and Mark D. White (Eds.). Oxford University Press, New York, 11-27.

[6] Icek Ajzen. 1991. The theory of planned behavior. Organizational Behavior and Human Decision Processes 50, 2 (1991), 179-211. https:
//doi.org/10.1016/0749-5978(91)90020-T

[7] Adam Alter. 2017. Irresistible: The Rise of Addictive Technology and the Business of Keeping Us Hooked. Penguin Press.

[8] Mg Ames. 2013. Managing mobile multitasking: the culture of iPhones on stanford campus. Computer Supported Cooperative Work (2013), 1487-1498. https://doi.org/10.1145/2441776.2441945

[9] Ionut Andone, Konrad Blaszkiewicz, Mark Eibes, Boris Trendafilov, Christian Montag, and Alexander Markowetz. 2016. Menthal: Quantifying Smartphone Usage. In Proceedings of the 2016 ACM International foint Conference on Pervasive and Ubiquitous Computing: Adjunct (UbiComp '16). ACM, New York, NY, USA, 559-564. https: //doi.org/10.1145/2968219.2968321

[10] Cecilie Schou Andreassen, Joël Billieux, Mark D. Griffiths, Daria J. Kuss, Zsolt Demetrovics, Elvis Mazzoni, and Ståle Pallesen. 2016. The relationship between addictive use of social media and video games and symptoms of psychiatric disorders: A large-scale crosssectional study. Psychology of Addictive Behaviors 30, 2 (2016), 252262. https://doi.org/10.1037/adb0000160

[11] Apple. 2018. iOS 12 introduces new features to reduce interruptions and manage Screen Time. https: //www.apple.com/uk/newsroom/2018/06/ios-12-introducesnew-features-to-reduce-interruptions-and-manage-screen-time/

[12] Dan Ariely and Klaus Wertenbroch. 2002. Procrastination, deadlines, and performance: self-control by precommitment. Psychological science 2000 (2002), 219-224. https://doi.org/10.1111/1467-9280.00441

[13] S. E. Asch. 1951. Opinions and Social Pressure. Scientific American. Scientific American 193 (1951), 31-35.

[14] Alan Baddeley. 2003. Working Memory: Looking Back and Looking Forward. Nature reviews. Neuroscience 4, October (2003), 829-839.

[15] Albert Bandura. 1991. Social Cognitive Theory of Self-Regulation. Organizational Behavior and Human Decision Processes 50, 2 (1991), 248-287. https://doi.org/10.1016/0749-5978(91)90022-L

[16] Alan Baron, M. Perone, and M. Galizio. 1991. Analyzing the reinforcement process at the human level: Can application and behavioristic interpretation replace laboratory research? The Behavior Analyst 14, 2 (1991), 95-105. https://doi.org/10.1111/1462-2920.12203

[17] Roy F. Baumeister and Julie Juola Exline. 2000. Self-control, Morality, and Human Strength. Journal of Social and Clinical Psychology 19, 1 (2000), 29-42.

[18] Roy F. Baumeister, Kathleen D Vohs, and Dianne M Tice. 2007. The Strength Model of Self-Control. Current Directions in Psychological Science 16, 6 (2007), 351-355. https://doi.org/10.1111/j.1467-8721. 2007.00534.x

[19] Eric Baumer and Phil Adams. 2013. Limiting, leaving, and (re) lapsing: an exploration of facebook non-use practices and experiences. Chi 2013 (2013), 3257-3266. https://doi.org/10.1145/2470654.2466446

[20] Jacqueline Lorene Bender, Rossini Ying Kwan Yue, Matthew Jason To, Laetitia Deacken, and Alejandro R Jadad. 2013. A Lot of Action, But Not in the Right Direction: Systematic Review and Content Analysis of Smartphone Applications for the Prevention, Detection, and Management of Cancer. J Med Internet Res 15, 12 (dec 2013), e287. https://doi.org/10.2196/jmir.2661

[21] Riley Bennett. 2018. Wormhole Escaper. https: //chrome.google.com/webstore/detail/wormhole-escaper/ jadgefoemafhcdkbhmeadkmodmpnfcak?hl=gb

[22] Elliot T Berkman, Cendri A Hutcherson, Jordan L Livingston, Lauren E Kahn, and Michael Inzlicht. 2017. Self-Control as Value-Based Choice. Current Directions in Psychological Science 26, 5 (2017), 422428. https://doi.org/10.1177/0963721417704394

[23] D. Bernoulli. 1954. Exposition of a new theory of the measurement of risk. Econometrica 22 (1954), 23-36. 
[24] Kent C. Berridge and Morten L. Kringelbach. 2015. Pleasure Systems in the Brain. Neuron 86, 3 (2015), 646-664. https://doi.org/10.1016/j. neuron.2015.02.018

[25] Bastien Blain, Guillaume Hollard, and Mathias Pessiglione. 2016. Neural mechanisms underlying the impact of daylong cognitive work on economic decisions. Proceedings of the National Academy of Sciences 113, 25 (2016), 6967-6972. https://doi.org/10.1073/pnas.1520527113

[26] Richard A. Block, P. A. Hancock, and Dan Zakay. 2010. How cognitive load affects duration judgments: A meta-analytic review. Acta Psychologica 134 (2010), 330-343. https://doi.org/10.1016/j.actpsy. 2010.03.006

[27] Jonas Nygaard Blom and Kenneth Reinecke Hansen. 2015. Click bait: Forward-reference as lure in online news headlines. fournal of Pragmatics 76 (2015), 87-100. https://doi.org/10.1016/j.pragma.2014. 11.010

[28] Matthew Botvinick and Todd S Braver. 2015. Motivation and cognitive control: From behavior to neural mechanism. Annual Review of Psychology 66 (2015), 83-113. https://doi.org/10.1146/annurev-psych010814-015044

[29] Matthew M Botvinick. 2008. Hierarchical models of behaviors and prefrontal function. Trends in Cognitive Sciences 12, 5 (2008), 201-208. https://doi.org/10.1016/j.tics.2008.02.009

[30] Boundless Mind Inc. 2018. Space - You Need a Breather. https://itunes.apple.com/gb/app/space-you-need-a-breather/ id1187106675? $\mathrm{mt}=8$ \&ign $-\mathrm{mpt}=\mathrm{uo} \% 3 \mathrm{D} 4$

[31] Gharad Bryan, Dean S. Karlan, and Scott Nelson. 2010. Commitment Devices. Annual Review of Economics 2 (2010), 671-698. https: //doi.org/10.1146/annurev.economics.102308.124324

[32] Thomas Caraco, Steven Martindale, and Thomas S. Whittam. 1980 An empirical demonstration of risk-sensitive foraging preferences. Animal Behaviour 28, 3 (aug 1980), 820-830. https://doi.org/10.1016/ S0003-3472(80)80142-4

[33] C. S. Carver and M. F. Scheier. 1981. Attention and self-regulation: A control-theory approach to human behavior. Springer-Verlag, New York.

[34] C. S. Carver and M. F. Scheier. 1998. On the self-regulation of behavior Cambridge University Press, New York.

[35] Josh Centers. 2018. Tim Cook Uses His iPhone Too Much. https: //tidbits.com/2018/06/07/tim-cook-uses-his-iphone-too-much/

[36] Kaustav Chakraborty, Debasish Basu, and K. G. Vijaya Kumar. 2010. Internet addiction: Consensus, controversies, and the way ahead. East Asian Archives of Psychiatry 20, 3 (2010), 123-132.

[37] Emily I M Collins, Anna L Cox, Jon Bird, and Cassie Cornish-Tresstail. 2014. Barriers to engagement with a personal informatics productivity tool. Proceedings of the 26th Australian Computer-Human Interaction Conference on Designing Futures the Future of Design - OzCHI '14 (2014), 370-379. https://doi.org/10.1145/2686612.2686668

[38] Sunny Consolvo, David W. McDonald, and James A. Landay. 2009. Theory-Driven Design Strategies for Technologies that Support Behavior Change in Everyday Life. In CHI $2009^{2}$ Creative Thought and Self-Improvement. Boston, Massachusetts, USA, 405-414.

[39] Christos Constantinidis and Xiao-Jing Wang. 2007. A Neural Circuit Basis for Spatial Working Memory. The Neuroscientist 10, 6 (2007) 553-565. https://doi.org/10.1177/1073858404268742

[40] Richard Cooper and Tim Shallice. 2000. Contention Scheduling and the Control of Routine Activities. Cognitive Neuropsychology 17, 4 (2000), 297-338. https://doi.org/10.1080/026432900380427

[41] Richard P. Cooper, Nicolas Ruh, and Denis Mareschal. 2014. The goal circuit model: A hierarchical multi-route model of the acquisition and control of routine sequential action in humans. Cognitive Science 38, 2 (2014), 244-274. https://doi.org/10.1111/ cogs.12067

[42] M Corbetta, F M Miezin, S Dobmeyer, G L Shulman, and S E Petersen 1991. Selective and divided attention during visual discriminations of shape, color, and speed: functional anatomy by positron emission tomography. The fournal of neuroscience : the official journal of the Society for Neuroscience 11, 8 (1991), 2383-402. http://www.ncbi.nlm. nih.gov/pubmed/1869921

[43] Steven S Coughlin, Mary Whitehead, Joyce Q Sheats, Jeff Mastromonico, Dale Hardy, and Selina A Smith. 2015. Smartphone Applications for Promoting Healthy Diet and Nutrition: A Literature Review. Jacobs journal of food and nutrition 2, 3 (2015), 021. https://doi.org/10.1038/nature13736.Tyrosine

[44] Nelson Cowan. 2010. The Magical Mystery Four: How is Working Memory Capacity Limited, and Why? Curr Dir Psychol Sci 19, 1 (2010), 51-57. https://doi.org/10.1177/0963721409359277

[45] Anna L Cox, Sandy J J Gould, Marta E Cecchinato, Ioanna Iacovides, and Ian Renfree. 2016. Design Frictions for Mindful Interactions: The Case for Microboundaries. In Proceedings of the 2016 CHI Conference Extended Abstracts on Human Factors in Computing Systems (CHI EA '16). ACM, New York, NY, USA, 1389-1397. https://doi.org/10.1145/ 2851581.2892410

[46] T S Critchfield and S H Kollins. 2001. Temporal discounting: basic research and the analysis of socially important behavior. fournal of applied behavior analysis 34, 1 (2001), 101-122. https://doi.org/10. 1901/jaba.2001.34-101

[47] Croshan. 2018. Pipe Clogger. https://chrome.google.com/webstore/ detail/pipe-clogger/hlaegcjcddgappcehdfoakpjnfpoaebl?hl=gb

[48] Laura Dabbish, Gloria Mark, and Víctor M. González. 2011. Why do i keep interrupting myself? Proceedings of the 2011 annual conference on Human factors in computing systems - CHI '11 (2011), 3127. https: //doi.org/10.1145/1978942.1979405

[49] Hengchen Dai, Katherine L. Milkman, David A. Hofmann, and Bradley R. Staats. 2015. The impact of time at work and time off from work on rule compliance: The case of hand hygiene in health care. Journal of Applied Psychology 100, 3 (may 2015), 846-862. https://doi.org/10.1037/a0038067

[50] T. H. Davenport and J. C. Beck. 2001. The Attention Economy: Understanding the New Currency of Business. Harvard Business School Press.

[51] Digital Wellness Warriors. 2018. Apple: let developers help iPhone users with mental wellbeing. https://www.change.org/p/appleallow-digital-wellness-developers-to-help-ios-users

[52] Paul Dolan, Antony Elliott, Robert Metcalfe, and Ivo Vlaev. 2012. Influencing Financial Behavior: From Changing Minds to Changing Contexts. Fournal of Behavioral Finance 13, 2 (2012), 126-142. https: //doi.org/10.1080/15427560.2012.680995

[53] Angela L. Duckworth, Tamar Szabó Gendler, and James J. Gross. 2014. Self Control in School Age Children. Educational Psychologist 49, 3 (2014), 199-217. https://doi.org/10.1080/00461520.2014.926225

[54] A. L. Duckworth, T. S. Gendler, and J. J. Gross. 2016. Situational Strategies for Self-Control. Perspectives on Psychological Science 11, 1 (2016). https://doi.org/10.1177/1745691615623247

[55] H E Egeth and S Yantis. 1997. Visual attention: control, representation, and time course. Annual review of psychology 48 (1997), 269-297. https://doi.org/10.1146/annurev.psych.48.1.269

[56] Mara Einstein. 2016. Black Ops Advertising. OR Books, New York.

[57] Jon D. Elhai, Jason C. Levine, Robert D. Dvorak, and Brian J. Hall. 2016. Fear of missing out, need for touch, anxiety and depression are related to problematic smartphone use. Computers in Human Behavior 63 (2016), 509-516. https://doi.org/10.1016/j.chb.2016.05.079

[58] Nicholas Epley and Thomas Gilovich. 1999. Just Going Along: Nonconscious Priming and Conformity to Social Pressure. Fournal of Experimental Social Psychology 35 (1999), 578-589. https: //doi.org/10.1006/jesp.1999.1390 
[59] Daniel A. Epstein, An Ping, James Fogarty, and Sean A. Munson. 2015. A lived informatics model of personal informatics. In Proceedings of the 2015 ACM International foint Conference on Pervasive and Ubiquitous Computing - UbiComp '15. 731-742. https: //doi.org/10.1145/2750858.2804250

[60] Owain Evans, Andreas Stuhl, Noah D. Goodman, Andreas Stuhlmüller, and Noah D. Goodman. 2016. Learning the Preferences of Ignorant, Inconsistent Agents. Proceedings of the Thirtieth AAAI Conference on Artificial Intelligence (2016), 323-329.

[61] Flipd Inc. 2018. Flipd. https://play.google.com/store/apps/details? id=com.flipd.app $\{\&\} \mathrm{hl}=\mathrm{en}\{\&\} \mathrm{gl}=\mathrm{us}$

[62] Jonathan Safran Foer. 2016. Technology is diminishing us https://www.theguardian.com/books/2016/dec/03/jonathan-safranfoer-technology-diminishing-us

[63] Kirsten Foot. 2014. The online emergence of pushback on social media in the United States: A historical discourse analysis. International fournal of Communication 8, 1 (2014), 1313-1342.

[64] A. Gazzaley, W. Clapp, J. Kelley, K. McEvoy, R. T. Knight, and M. D'Esposito. 2008. Age-related top-down suppression deficit in the early stages of cortical visual memory processing. Proceedings of the National Academy of Sciences 105, 35 (2008), 13122-13126. https: //doi.org/10.1073/pnas.0806074105

[65] Henner Gimpel, Christian Regal, and Marco Schmidt. 2015. myStress: Unobtrusive Smartphone-Based Stress Detection. ECIS 2015 (2015), 0-12. http://aisel.aisnet.org/cgi/viewcontent.cgi?article= 1015\&context=ecis2015_rip

[66] Peter M. Gollwitzer and Paschal Sheeran. 2006. Implementation Intentions and Goal Achievement: A Meta-analysis of Effects and Processes. Advances in Experimental Social Psychology 38 (2006) 69-119. https://doi.org/10.1016/S0065-2601(06)38002-1

[67] Robbie Gonzalez. 2018. The Research Behind Google's New Tools for Digital Well-Being. Wired (may 2018). https://www.wired.com/story/ the-research-behind-googles-new-tools-for-digital-well-being/

[68] Google. 2018. Digital Wellbeing. https://wellbeing.google

[69] Google Play. 2017. Forest: Stay focused. https://play.google.com/ store/apps/details?id=cc.forestapp\&hl=en_GB

[70] David H Gustafson, Michael G. Boyle, Bret R. Shaw, and Fiona M McTavish. 2011. An E-health solution for people with alcohol problems Alcohol Res Health 33, 4 (2011), 327-337. https://doi.org/10.1038/jid. 2014.371

[71] Anthony Ha. 2012. The Phone Stacking Game: Let's Make This A Thing. https://techcrunch.com/2012/02/04/the-phone-stackinggame-lets-make-this-a-thing/

[72] Martin S Hagger, Nikos L D Chatzisarantis, Hugo Alberts, Calvin Octavianus Anggono, Cédric Batailler, Angela R Birt, Ralf Brand, Mark J Brandt, Gene Brewer, Sabrina Bruyneel, Dustin P Calvillo, W Keith Campbell, Peter R Cannon, Marianna Carlucci, Nicholas P Carruth, Tracy Cheung, Adrienne Crowell, Denise T D De Ridder, Siegfried Dewitte, Malte Elson, Jacqueline R Evans, Benjamin A Fay, Bob M Fennis, Anna Finley, Zoë Francis, Elke Heise, Henrik Hoemann, Michael Inzlicht, Sander L Koole, Lina Koppel, Floor Kroese, Florian Lange, Kevin Lau, Bridget P Lynch, Carolien Martijn, Harald Merckelbach, Nicole V Mills, Alexej Michirev, Akira Miyake, Alexandra E Mosser, Megan Muise, Dominique Muller, Milena Muzi, Dario Nalis, Ratri Nurwanti, Henry Otgaar, Michael C Philipp, Pierpaolo Primoceri, Katrin Rentzsch, Lara Ringos, Caroline Schlinkert, Brandon J Schmeichel, Sarah F Schoch, Michel Schrama, Astrid Schütz, Angelos Stamos, Gustav Tinghög, Johannes Ullrich, Michelle Vandellen, Supra Wimbarti, Wanja Wolff, Cleoputri Yusainy, Oulmann Zerhouni, Maria Zwienenberg, Chandra Sripada, Daniel Kessler, and Roy Baumeister. 2016. A Multilab Preregistered Replication of the Ego-Depletion Effect. Perspectives on Psychological Science 11, 4 (2016), 546-573. https://doi.org/10.1177/1745691616652873

[73] Martin S Hagger, Chantelle Wood, Chris Stiff, and Nikos L D Chatzisarantis. 2010. Ego depletion and the strength model of self-control: a meta-analysis. Psychological bulletin 136, 4 (2010), 495-525. https: //doi.org/10.1037/a0019486

[74] Wendy Hardeman, Stephen Sutton, Simon Griffin, Marie Johnston, Anthony White, Nicholas J. Wareham, and Ann Louise Kinmonth. 2005. A causal modelling approach to the development of theorybased behaviour change programmes for trial evaluation. Health Education Research 20, 6 (2005), 676-687. https://doi.org/10.1093/ her/cyh022

[75] Tristan Harris. 2016. How Technology Hijacks People's Minds - from a Magician and Google's Design Ethicist. http://www.huffingtonpost.com/tristan-harris/how-technologyhijacks-peoples-minds_b_10155754.html

[76] Jaimee L. Heffner, Roger Vilardaga, Laina D. Mercer, Julie A. Kientz, and Jonathan B. Bricker. 2015. Feature-level analysis of a novel smartphone application for smoking cessation. The American fournal of Drug and Alcohol Abuse 41, 1 (2015), 68-73. https://doi.org/10. 3109/00952990.2014.977486

[77] Christian S Hendershot, Katie Witkiewitz, William H George, and G Alan Marlatt. 2011. Relapse prevention for addictive behaviors. Substance Abuse Treatment, Prevention, and Policy 6, 1 (2011), 17. https://doi.org/10.1186/1747-597X-6-17

[78] Alexis Hiniker, Sungsoo Ray Hong, Tadayoshi Kohno, and Julie A Kientz. 2016. MyTime: Designing and Evaluating an Intervention for Smartphone Non-Use. Proceedings of the 2016 CHI Conference on Human Factors in Computing Systems (2016), 4746-4757. https: //doi.org/10.1145/2858036.2858403

[79] Robert Hockey. 2013. The Psychology of Fatigue: Work, Effort and Control. Cambridge University Press. https://doi.org/10.1017/ CBO9781139015394

[80] Wilhelm Hofmann, Kathleen D. Vohs, and Roy F. Baumeister. 2012. What People Desire, Feel Conflicted About, and Try to Resist in Everyday Life. Psychological Science 23, 6 (2012), 582-588. https: //doi.org/10.1177/0956797612437426

[81] Michael Inzlicht, Lisa Legault, and Rimma Teper. 2014. Exploring the Mechanisms of Self-Control Improvement. Current Directions in Psychological Science 23, 4 (2014), 302-307. https://doi.org/10.1177/ 0963721414534256

[82] Michael Inzlicht, Brandon J. Schmeichel, and C. Neil Macrae. 2014. Why self-control seems (but may not be) limited. Trends in Cognitive Sciences 18, 3 (2014), 127-133. https://doi.org/10.1016/j.tics.2013.12. 009

[83] L Itti and C Koch. 2001. Computational modelling of visual attention. Nature reviews. Neuroscience 2, 3 (2001), 194-203. https://doi.org/10. $1038 / 35058500$

[84] B A Iwata. 1987. Negative reinforcement in applied behavior analysis: an emerging technology. Fournal of Applied Behavior Analysis 20, 4 (1987), 361-378. https://doi.org/10.1901/jaba.1987.20-361

[85] Daniel Kahneman. 2011. Thinking, fast and slow. Allen Lane (Penguin), New York.

[86] Daniel Kahneman and Amos Tversky. 1979. Prospect Theory: An Analysis of Decision Under Risk. Econometrica 47, 2 (1979), 263-292.

[87] Elisabeth T. Kersten-van Dijk, Joyce H.D.M. Westerink, Femke Beute, and Wijnand A. IJsselsteijn. 2017. Personal Informatics, Self-Insight, and Behavior Change: A Critical Review of Current Literature. $\mathrm{Hu}$ man-Computer Interaction 32, 5-6 (2017), 268-296. https://doi.org/ 10.1080/07370024.2016.1276456

[88] Inyeop Kim, Gyuwon Jung, Hayoung Jung, Minsam Ko, and Uichin Lee. 2017. Let's FOCUS: Mitigating Mobile Phone Use in College Classrooms. Proc. ACM Interact. Mob. Wearable Ubiquitous Technol. 1, 
3 (sep 2017), 63:1--63:29. https://doi.org/10.1145/3130928

[89] Jaejeung Kim, Chiwoo Cho, and Uichin Lee. 2017. Technology Supported Behavior Restriction for Mitigating Self-Interruptions in Multi-device Environments. Proceedings of the ACM on Interactive, Mobile, Wearable and Ubiquitous Technologies 1, 3 (sep 2017), 1-21. https://doi.org/10.1145/3130932

[90] Young-Ho Kim, Jae Ho Jeon, Eun Kyoung Choe, Bongshin Lee, KwonHyun Kim, and Jinwook Seo. 2016. TimeAware: Leveraging Framing Effects to Enhance Personal Productivity. In Proceedings of the 2016 CHI Conference on Human Factors in Computing Systems (CHI '16). ACM, New York, NY, USA, 272-283. https://doi.org/10.1145/2858036. 2858428

[91] Jake Knapp. 2013. The distraction-free iPhone (or 'Why I'm happier since I disabled Safari'). https://medium.com/time-dorks/thedistraction-free-iphone-or-why-im-happier-since-i-disabledsafari-80f8d525b0d8

[92] Eric I Knudsen. 2007. Fundamental Components of Attention. Annual review of neuroscience 30 (2007), 57-78. https://doi.org/10.1146/ annurev.neuro.30.051606.094256

[93] Minsam Ko, Seungwoo Choi, Koji Yatani, and Uichin Lee. 2016. Lock N' LoL: Group-based Limiting Assistance App to Mitigate Smartphone Distractions in Group Activities. In Proceedings of the 2016 CHI Conference on Human Factors in Computing Systems. ACM, New York, 998-1010. https://doi.org/10.1145/2858036.2858568

[94] Minsam Ko, Kyong-Mee Chung, Subin Yang, Joonwon Lee, Christian Heizmann, Jinyoung Jeong, Uichin Lee, Daehee Shin, Koji Yatani, and Junehwa Song. 2015. NUGU: A Group-based Intervention App for Improving Self-Regulation of Limiting Smartphone Use. Proceedings of the 18th ACM Conference on Computer Supported Cooperative Work \& Social Computing - CSCW'15 (2015), 1235-1245. https://doi.org/ 10.1145/2675133.2675244

[95] Artie Konrad, Vitoria Belotti, Nicole Crenshaw, Simon Tucker, Les Nelson, Honglu Du, Peter Pirolli, Steve Whittaker, Steve Whittaker Artie Konrad, Vitoria Belotti, Nicole Crenshaw, Simon Tucker, Les Nelson, Honglu Du, Peter Pirolli, Artie Konrad, Vitoria Belotti, Nicole Crenshaw, Simon Tucker, Les Nelson, Honglu Du, Peter Pirolli, and Steve Whittaker. 2015. Finding the Adaptive Sweet Spot: Balancing Compliance and Achievement in Automated Stress Reduction. Proceedings of the 33rd Annual ACM Conference on Human Factors in Computing Systems - CHI '15 (2015), 3829-3838. https: //doi.org/10.1145/2702123.2702512

[96] Hiroki P. Kotabe and Wilhelm Hofmann. 2015. On Integrating the Components of Self-Control. Perspectives on Psychological Science 10, 5 (2015), 618-638. https://doi.org/10.1177/1745691615593382

[97] Geza Kovacs, Zhengxuan Wu, and Michael S Bernstein. 2018. Rotating Online Behavior Change Interventions Increases Effectiveness But Also Increases Attrition. Proc. ACM Hum.-Comput. Interact. 2, CSCW (nov 2018), 95:1--95:25. https://doi.org/10.1145/3274364

[98] S. Shunmuga Krishnan and Ramesh K. Sitaraman. 2013. Video stream quality impacts viewer behavior: Inferring causality using quasiexperimental designs. IEEE/ACM Transactions on Networking 21, 6 (2013), 2001-2014. https://doi.org/10.1109/TNET.2013.2281542

[99] Florian Lange and Frank Eggert. 2014. Sweet delusion: Glucose drinks fail to counteract ego depletion. Appetite 75, July 2015 (2014), 54-63. https://doi.org/10.1016/j.appet.2013.12.020

[100] Heyoung Lee, Heejune Ahn, Samwook Choi, and Wanbok Choi. 2014 The SAMS: Smartphone addiction management system and verification. fournal of Medical Systems 38, 1 (2014). https://doi.org/10.1007/ s10916-013-0001-1

[101] U Lee, J Lee, Minsam Ko, Changhun Lee, and Yuhwan Kim. 2014. Hooked on smartphones: an exploratory study on smartphone overuse among college students. In Proceedings of the SIGCHI Conference on Human Factors in Computing Systems (CHI'14). ACM, New York, 2327-2336. https://doi.org/10.1145/2556288.2557366

[102] Ian Leslie. 2016. The scientists who make apps addictive. The Economist (2016). https://www.1843magazine.com/features/the-scientistswho-make-apps-addictive

[103] Ian Li, Anind Dey, and Jodi Forlizzi. 2010. A stage-based model of personal informatics systems. In Proceedings of the 28th international conference on Human factors in computing systems - CHI '10. 557. https://doi.org/10.1145/1753326.1753409

[104] Hajin Lim, Ian Arawjo, Yaxian Xie, Negar Khojasteh, and Susan R Fussell. 2017. Distraction or Life Saver? The Role of Technology in Undergraduate Students' Boundary Management Strategies. Proceedings of the ACM on Human-Computer Interaction 1, CSCW, November (2017). https://doi.org/10.1145/3134703

[105] Markus Löchtefeld, Matthias Böhmer, and Lyubomir Ganev. 2013. AppDetox. Proceedings of the 12th International Conference on Mobile and Ubiquitous Multimedia - MUM '13 (2013), 1-2. https://doi.org/ $10.1145 / 2541831.2541870$

[106] Edwin A. Locke and Gary P. Latham. 2002. Building a practically useful theory of goal setting and task motivation: A 35-year odyssey. American Psychologist 57, 9 (2002), 705-717. https://doi.org/10.1037/ 0003-066X.57.9.705

[107] Danielle Lottridge, Eli Marschner, Ellen Wang, Maria Romanovsky, and Clifford Nass. 2012. Browser design impacts multitasking. In Proceedings of the Human Factors and Ergonomics Society 56th Annual Meeting. https://doi.org/10.1177/1071181312561289

[108] Arlene R Lundquist, Emily J Lefebvre, and Sara J Garramone. 2014. Smartphones: Fulfilling the need for immediacy in everyday life, but at what cost? International fournal of Humanities and Social Science 4, 2 (2014), 80-89.

[109] John H. Lurquin and Akira Miyake. 2017. Challenges to ego-depletion research go beyond the replication crisis: A need for tackling the conceptual crisis. Frontiers in Psychology 8, APR (2017), 1-5. https: //doi.org/10.3389/fpsyg.2017.00568

[110] Ulrik Lyngs. 2018. A Cognitive Design Space for Supporting SelfRegulation of ICT Use. In Extended Abstracts of the 2018 CHI Conference on Human Factors in Computing Systems (CHI EA '18). ACM, New York, NY, USA, SRC14:1--SRC14:6. https://doi.org/10.1145/ 3170427.3180296

[111] Ulrik Lyngs. 2018. CHI Proceedings R Markdown Template. https: //github.com/ulyngs/chi-proc-rmd-template

[112] Ulrik Lyngs, Reuben Binns, Max Van Kleek, and Nigel Shadbolt. 2018. "So, Tell Me What Users Want, What They Really, Really Want!". In Extended Abstracts of the 2018 CHI Conference on Human Factors in Computing Systems (CHI EA '18). ACM, New York, NY, USA, alt04:1-alt04:10. https://doi.org/10.1145/3170427.3188397

[113] Claudia Marino, Gianluca Gini, Alessio Vieno, and Marcantonio M. Spada. 2018. A comprehensive meta-analysis on Problematic Facebook Use. Computers in Human Behavior 83 (2018), 262-277. https: //doi.org/10.1016/j.chb.2018.02.009

[114] Claudia Marino, Gianluca Gini, Alessio Vieno, and Marcantonio M. Spada. 2018. The associations between problematic Facebook use, psychological distress and well-being among adolescents and young adults: A systematic review and meta-analysis. Fournal of Affective Disorders 226, September 2017 (2018), 274-281. https://doi.org/10. 1016/j.jad.2017.10.007

[115] Gloria Mark, Mary Czerwinski, and Shamsi T Iqbal. 2018. Effects of Individual Differences in Blocking Workplace Distractions. In Proceedings of the 2018 CHI Conference on Human Factors in Computing Systems (CHI '18). ACM, New York, NY, USA, 92:1--92:12. https://doi.org/10.1145/3173574.3173666 
[116] Gloria Mark, Shamsi Iqbal, and Mary Czerwinski. 2017. How Blocking Distractions Affects Workplace Focus and Productivity. In UbiComp/ISWC'17 Adjunct. Maui, HI, USA, 928-934. https://doi.org/10. 1145/3123024.3124558

[117] Veronica Marotta and Alessandro Acquisti. 2017. Online Distractions, Website Blockers, and Economic Productivity: A Randomized Field Experiment. (2017). https://weis2017.econinfosec.org/wp-content/ uploads/sites/3/2017/06/WEIS\{_\}2017__\}paper__\}26.pdf

[118] Theresa M. Marteau. 1989. Framing of information: Its influence upon decisions of doctors and patients. British fournal of Social Psychology Mar, 28 (1989), 89-94. https://doi.org/10.1111/j.20448309.1989.tb00849.x

[119] S. M. McClure, K. M. Ericson, D. I. Laibson, G. Loewenstein, and J. D. Cohen. 2007. Time Discounting for Primary Rewards. fournal of Neuroscience 27, 21 (2007), 5796-5804. https://doi.org/10.1523/ JNEUROSCI.4246-06.2007

[120] Robert R. McCrae and Paul T. Costa, Jr. 1999. A Five-Factor theory of personality. In Handbook of Personality: Theory and Research, L. A. Pervin and O. P. John (Eds.). Guildford Press, New York, NY, USA, 139-153. https://doi.org/10.1007/978-1-4615-0763-5_11

[121] Brandon T. McDaniel and Sarah M. Coyne. 2014. "Technoference": The interference of technology in couple relationships and implications for women's personal and relational well-being. Psychology of Popular Media Culture 5, 1 (2014), Advance online publication. https://doi.org/10.1037/ppm0000065

[122] Susan Michie, Marie Johnston, Jill Francis, Wendy Hardeman, and Martin Eccles. 2008. From Theory to Intervention: Mapping Theoretically Derived Behavioural Determinants to Behaviour Change Techniques. Applied Psychology 57, 4 (2008), 660-680. https: //doi.org/10.1111/j.1464-0597.2008.00341.x

[123] Milk The Moment Inc. 2018. The MILK App. https://itunes.apple. $\mathrm{com} / \mathrm{gb} / \mathrm{app} /$ the-milk-app/id1340000116? $\mathrm{mt}=8$ \&ign- $\mathrm{mpt}=\mathrm{uo} \% 3 \mathrm{D} 4$

[124] Brian T. Miller and Mark D’Esposito. 2005. Searching for "the top" in top-down control. Neuron 48, 4 (2005), 535-538. https://doi.org/10. 1016/j.neuron.2005.11.002

[125] E K Miller and J D Cohen. 2001. An integrative theory of prefrontal cortex function. Annual review of neuroscience 24, 1 (2001), 167-202. https://doi.org/10.1146/annurev.neuro.24.1.167

[126] George A. Miller. 1956. The magical number seven, plus or minus two: some limits on our capacity for processing information. Psychological review 63, 2 (1956), 343-352. https://doi.org/10.1037/h0043158

[127] W. R. Miller, V. S. Westerberg, R. J. Harris, and J. S. Tonigan. 1996. What predicts relapse? Prospective testing of antecedent models. Addiction 91, SUPPL. (1996). https://doi.org/10.1111/j.1360-0443. 1996.tb02336.x

[128] Marina Milyavskaya and Michael Inzlicht. 2018. Attentional and Motivational Mechanisms of Self-Control. Handbook of Self-Control in Health \& Well- Being (2018), 11-23. https://doi.org/10.1017/ CBO9781107415324.004

[129] D. C. Molden, C. M. Hui, a. a. Scholer, B. P. Meier, E. E. Noreen, P. R. D’Agostino, and V. Martin. 2012. Motivational Versus Metabolic Effects of Carbohydrates on Self-Control. Psychological Science 23, 10 (2012), 1137-1144. https://doi.org/10.1177/0956797612439069

[130] Christian Montag, Alexander Markowetz, Konrad Blaszkiewicz, Ionut Andone, Bernd Lachmann, Rayna Sariyska, Boris Trendafilov, Mark Eibes, Julia Kolb, Martin Reuter, Bernd Weber, and Sebastian Markett. 2017. Facebook usage on smartphones and gray matter volume of the nucleus accumbens. Behavioural Brain Research 329, April (2017), 221-228. https://doi.org/10.1016/j.bbr.2017.04.035

[131] Lela Mosemghvdlishvili and Jeroen Jansz. 2013. Negotiability of technology and its limitations: The politics of App development.
Information, Communication \& Society 16, 10 (dec 2013), 1596-1618.

[132] James R Müller, Marios G Philiastides, and William T Newsome. 2005. Microstimulation of the superior colliculus focuses attention without moving the eyes. Proceedings of the National Academy of Sciences of the United States of America 102, 3 (2005), 524-9. https: //doi.org/10.1073/pnas.0408311101

[133] Mark Muraven and Elisaveta Slessareva. 2003. Mechanisms of SelfControl Failure: Motivation and Limited Resources. Personality and Social Psychology Bulletin 29, 7 (2003), 894-906. https://doi.org/10. 1177/0146167203253209

[134] D.A. Norman and T. Shallice. 1986. Attention to Action: Willed and Automatic Control of Behaviour. In Consciousness and Self-regulation (Advances in Research and Theory, Vol. 4), R.J. et al. Davidson (Ed.). Plenum, 1-18.

[135] Ted O’Donoghue and Matthew Rabin. 2001. Choice and Procrastination. Quarterly fournal of Economics 116, 1 (2001), 121-160. https://doi.org/10.1162/003355301556365

[136] Fabian Okeke, Michael Sobolev, Nichola Dell, and Deborah Estrin. 2018. Good Vibrations: Can a Digital Nudge Reduce Digital Overload?. In Proceedings of MobileHCI '18: 20th International Conference on Human-Computer Interaction with Mobile Devices and Services, Barcelona, Spain, September 3-6, 2018. https://doi.org/10.1145/ 3229434.3229463

[137] Bendegul Okumus, Anil Bilgihan, and Ahmet Bulent Ozturk. 2016. Factors Affecting the Acceptance of Smartphone Diet Applications. Journal of Hospitality Marketing and Management 25, 6 (2016), 726747. https://doi.org/10.1080/19368623.2016.1082454

[138] Facundo Olano. 2018. app-store-scraper. https://github.com/ facundoolano/app-store-scraper

[139] Facundo Olano. 2018. google-play-scraper. https://github.com/ facundoolano/google-play-scraper

[140] Rita Orji and Karyn Moffatt. 2018. Persuasive technology for health and wellness: State-of-the-art and emerging trends. Health Informatics fournal 24, 1 (2018), 66-91. https://doi.org/10.1177/ 1460458216650979

[141] Antti Oulasvirta, Tye Rattenbury, Lingyi Ma, and Eeva Raita. 2012. Habits make smartphone use more pervasive. Personal and Ubiquitous Computing 16, 1 (2012), 105-114. https://doi.org/10.1007/s00779-0110412-2

[142] Srikanth Padmala and Luiz Pessoa. 2010. Interactions between cognition and motivation during response inhibition. Neuropsychologia 48, 2 (2010), 558-565. https://doi.org/10.1016/j.neuropsychologia.2009. 10.017

[143] Srikanth Padmala and Luiz Pessoa. 2011. Reward reduces conflict by enhancing attentional control and biasing visual cortical processing. Journal of Cognitive Neuroscience 23, 11 (2011), 3419-3432. https: //doi.org/10.1162/jocn_a_00011

[144] Pavlok. 2018. PAVLOK Productivity. https:// chrome.google.com/webstore/detail/pavlok-productivity/ hefieeppocndiofffcfpkbfnjcooacib?hl=gb

[145] Charlie Pinder, Jo Vermeulen, Benjamin R. Cowan, and Russell Beale. 2018. Digital Behaviour Change Interventions to Break and Form Habits. ACM Transactions on Computer-Human Interaction 25, 3 (2018), 1-66. https://doi.org/10.1145/3196830

[146] Charlie Pinder, Jo Vermeulen, Benjamin R. Cowan, Russell Beale, and Robert J. Hendley. 2017. Exploring the feasibility of subliminal priming on smartphones. In Proceedings of the 19th International Conference on Human-Computer Interaction with Mobile Devices and Services - MobileHCI '17. https://doi.org/10.1145/3098279.3098531

[147] Adam Popescu. 2018. Keep Your Head Up: How Smartphone Addiction Kills Manners and Moods. https://www.nytimes.com/2018/01/ 25/smarter-living/bad-text-posture-neckpain-mood.html 
[148] Laura Portwood-Stacer. 2012. Media refusal and conspicuous nonconsumption: The performative and political dimensions of Facebook abstention. New Media \& Society 15, 7 (2012), 1041-1057. https: //doi.org/10.1177/1461444812465139

[149] W. T. Powers. 1973. Behavior: The control of perception. Aldine, Chicago.

[150] Prettymind.co. 2018. Timewaste Timer. https: //chrome.google.com/webstore/detail/timewaste-timer/ pengblgbipcdkpigibniogojheaokckd?hl=gb

[151] James O. Prochaska, Carlo C. DiClemente, and John C. Norcross. 1993. In Search of How People Change: Applications to Addictive Behaviors. Fournal of Addictions Nursing 5, 1 (1993), 2-16. https: //doi.org/10.3109/10884609309149692

[152] Andrew K. Przybylski, Kou Murayama, Cody R. Dehaan, and Valerie Gladwell. 2013. Motivational, emotional, and behavioral correlates of fear of missing out. Computers in Human Behavior 29, 4 (2013), 1841-1848. https://doi.org/10.1016/j.chb.2013.02.014

[153] Ameet Ranadive and David Ginsberg. 2018. New Tools to Manage Your Time on Facebook and Instagram. https://newsroom.fb.com/ news/2018/08/manage-your-time/

[154] Wenjie Ruan, Quan Z. Sheng, Lina Yao, Nguyen Khoi Tran, and Yu Chieh Yang. 2016. PreventDark: Automatically detecting and preventing problematic use of smartphones in darkness. In 2016 IEEE International Conference on Pervasive Computing and Communication Workshops (PerCom Workshops). 1-3. https://doi.org/10.1109/ PERCOMW.2016.7457071

[155] Runnably. 2019. Bashful. https://play.google.com/store/apps/details? id=com.runnably.bashful\&hl=en\&gl=us

[156] Tracii Ryan, Andrea Chester, John Reece, and Sophia Xenos. 2014 The uses and abuses of Facebook: A review of Facebook addiction. Journal of Behavioural Addictions 3, 3 (2014), 133-148. https://doi. org/10.1556/JBA.3.2014.016

[157] M. Sapacz, G. Rockman, and J. Clark. 2016. Are we addicted to our cell phones? Computers in Human Behavior 57 (2016), 153-159. https://doi.org/10.1016/j.chb.2015.12.004

[158] Christine Satchell and Paul Dourish. 2009. Beyond The User: Use And Non-Use in HCI. Proceedings of the Annual Conference of the Australian Computer-Human Interaction Special Interest Group (OZCHI '09) November (2009), 9-16. https://doi.org/10.1145/1738826.1738829

[159] Sarita Yardi Schoenebeck. 2014. Giving up Twitter for Lent: How and Why We Take Breaks from Social Media. Proceedings of the 32nd annual ACM conference on Human factors in computing systems - CHI '14 (2014), 773-782. https://doi.org/10.1145/2556288.2556983

[160] Stephen M. Schueller, Ricardo F. Muñoz, and David C. Mohr. 2013. Realizing the Potential of Behavioral Intervention Technologies. Current Directions in Psychological Science 22, 6 (2013), 478-483. https://doi.org/10.1177/0963721413495872

[161] Natasha Dow Schüll. 2012. Addiction By Design - Machine Gambling in Las Vegas. Princeton University Press, New Jersey.

[162] Willem Schungel. 2018. Checkout of your phone. https://itunes.apple. $\mathrm{com} / \mathrm{gb} / \mathrm{app} /$ checkout- of-your-phone/id1051880452? $\mathrm{mt}=8 \& \mathrm{uo}=4$

[163] Seekrtech. 2018. Forest: Stay focused. https://www.forestapp.cc

[164] Tim Shallice and Richard P. Cooper. 2011. The Organisation of Mind. Oxford University Press, Oxford.

[165] Nicholas Shea, Annika Boldt, Dan Bang, Nick Yeung, Cecilia Heyes, and Chris D Frith. 2014. Supra-personal cognitive control and metacognition. Trends in Cognitive Sciences 18, 4 (2014), 186-193. https://doi.org/10.1016/j.tics.2014.01.006

[166] Nelson Shen, Michael-Jane Levitan, Andrew Johnson, Jacqueline Lorene Bender, Michelle Hamilton-Page, Alejandro (Alex) R Jadad, and David Wiljer. 2015. Finding a Depression App: A Review and Content Analysis of the Depression App Marketplace. $7 M I R$
mHealth and $u$ Health 3, 1 (2015), e16. https://doi.org/10.2196/mhealth. 3713

[167] Amitai Shenhav, Matthew M Botvinick, and Jonathan D Cohen. 2013. The Expected Value of Control: An Integrative Theory of Anterior Cingulate Cortex Function. Neuron 79, 2 (2013), 217-240. https: //doi.org/10.1016/j.neuron.2013.07.007

[168] Amitai Shenhav, Sebastian Musslick, Falk Lieder, Wouter Kool, Thomas L Griffiths, Jonathan D Cohen, and Matthew M Botvinick. 2017. Toward a Rational and Mechanistic Account of Mental Effort. Annual Review of Neuroscience 40, 1 (jul 2017), 99-124. https: //doi.org/10.1146/annurev-neuro-072116-031526

[169] Steven J. Sherman. 1980. On the self-erasing nature of errors of prediction. Journal of Personality and Social Psychology 39, 2 (1980), 211-221. https://doi.org/10.1037/0022-3514.39.2.211

[170] Richard M. Shiffrin and Walter Schneider. 1977. Controlled and automatic human information processing: II. Perceptual learning, automatic attending and a general theory. Psychological Review 84, 2 (1977), 127-190. https://doi.org/10.1037/0033-295X.84.2.127

[171] Yousheng Shu, Andrea Hasenstaub, and David A. McCormick. 2003. Turning on and off recurrent balanced cortical activity. Nature 423, May (2003), 288-293. https://doi.org/10.1038/nature01614.1.

[172] Adam Slack. 2018. chrome-web-store-scraper. https://github.com/ AdamSlack/chrome-web-store-scraper

[173] Manya Sleeper, Alessandro Acquisti, Lorrie Faith Cranor, Patrick Gage Kelley, Sean A. Munson, and Norman Sadeh. 2015. I Would Like To..., I Shouldn't..., I Wish I... Proceedings of the 18th ACM Conference on Computer Supported Cooperative Work \& Social Computing - CSCW '15 (2015), 1058-1069. https://doi.org/10.1145/2675133.2675193

[174] Eliot R. Smith and Jamie DeCoster. 2000. Dual-Process Models in Social and Cognitive Psychology: Conceptual Integration and Links to Underlying Memory Systems. Personality and Social Psychology Review 4, 2 (2000), 108-131. https://doi.org/10.1207/ S15327957PSPR0402_01

[175] MobileSoft s.r.o. 2019. AppBlock. https://play.google.com/store/ apps/details?id=cz.mobilesoft.appblock\&hl=en\&gl=us

[176] Stanford HCI Group. 2018. HabitLab for Chrome (Extension for Google Chrome web browser). https://habitlab.stanford.edu/

[177] Katarzyna Stawarz, Anna L Cox, and Ann Blandford. 2014. Don't Forget Your Pill!: Designing Effective Medication Reminder Apps That Support Users' Daily Routines. In Proceedings of the SIGCHI Conference on Human Factors in Computing Systems (CHI '14). ACM, New York, NY, USA, 2269-2278. https://doi.org/10.1145/2556288.2557079

[178] Katarzyna Stawarz, Anna L Cox, and Ann Blandford. 2015. Beyond Self-Tracking and Reminders: Designing Smartphone Apps That Support Habit Formation. In Proceedings of the 33rd Annual ACM Conference on Human Factors in Computing Systems (CHI '15). ACM, New York, NY, USA, 2653-2662. https://doi.org/10.1145/2702123.2702230

[179] Katarzyna Stawarz, Chris Preist, Debbie Tallon, Nicola Wiles, and David Coyle. 2018. User experience of cognitive behavioral therapy apps for depression: An analysis of app functionality and user reviews. Journal of Medical Internet Research 20, 6 (2018). https://doi.org/10. 2196/10120

[180] Piers Steel and Cornelius J. König. 2006. Integrating theories of motivation. Academy of Management Review 31, 4 (2006), 889-913. https://doi.org/10.5465/AMR.2006.22527462

[181] Cary Stothart, Ainsley Mitchum, and Courtney Yehnert. 2015. The attentional cost of receiving a cell phone notification. Fournal of Experimental Psychology: Human Perception and Performance 41, 4 (2015), 893-897. https://doi.org/10.1037/xhp0000100

[182] Stringinternational.com. 2018. Timewarp. https: //chrome.google.com/webstore/detail/timewarp/ 
mmmhadpnjmokjbmgamifipkjddhlfkhi?hl=gb

[183] Cass R. Sunstein and Richard H. Thaler. 2008. Nudge. Penguin, London.

[184] Caroline Tell. 2013. Step Away From the Phone! https://www. nytimes.com/2013/09/22/fashion/step-away-from-the-phone.html

[185] Virginia Thomas, Margarita Azmitia, and Steve Whittaker. 2016. Unplugged: Exploring the costs and benefits of constant connection. Computers in Human Behavior 63 (2016), 540-548. https: //doi.org/10.1016/j.chb.2016.05.078

[186] D M Tice, E Bratslavsky, and R F Baumeister. 2001. Emotional distress regulation takes precedence over impulse control: if you feel bad, do it! fournal of personality and social psychology 80, 1 (2001), 53-67. https://doi.org/10.1037/0022-3514.80.1.53

[187] Nitasha Tiku. 2018. The WIRED Guide to Internet Addiction. https: //www.wired.com/story/wired-guide-to-internet-addiction/

[188] Trevorscandalios. 2018. Focusly. https://chrome.google.com/ webstore/detail/focusly/jlihnplddpebplnfafhdanaiapbeikbk?hl=gb

[189] Alexander J.A.M. Van Deursen, Colin L. Bolle, Sabrina M. Hegner, and Piet A.M. Kommers. 2015. Modeling habitual and addictive smartphone behavior: The role of smartphone usage types, emotional intelligence, social stress, self-regulation, age, and gender. Computers in Human Behavior 45, April (2015), 411-420. https://doi.org/10.1016/ j.chb.2014.12.039

[190] Michelle H. van Velthoven, John Powell, and Georgina Powell. 2018. Problematic smartphone use: Digital approaches to an emerging public health problem. Digital Health 4 (2018), 1-9. https://doi.org/ 10.1177/2055207618759167

[191] Kathleen D. Vohs and Roy F. Baumeister (Eds.). 2016. Handbook of Self-Regulation - Research, Theory, and Applications. Guildford Press, New York, NY, USA.

[192] V. H. Vroom. 1964. Work and Motivation. Wiley, New York.

[193] Jingting Wang, Yuanyuan Wang, Chunlan Wei, Nengliang Aaron Yao, Avery Yuan, Yuying Shan, and Changrong Yuan. 2014. Smartphone interventions for long-term health management of chronic diseases: an integrative review. Telemedicine journal and e-health: the official journal of the American Telemedicine Association 20, 6 (2014), 570-583. https://doi.org/10.1089/tmj.2013.0243

[194] Thomas L. Webb, Judith Joseph, Lucy Yardley, and Susan Michie. 2010. Using the Internet to promote health behavior change: A systematic review and meta-analysis of the impact of theoretical basis, use of behavior change techniques, and mode of delivery on efficacy. Journal of Medical Internet Research 12, 1 (2010), e4. https://doi.org/10.2196/ jmir.1376

[195] Steve Whittaker, Vaiva Kalnikaite, Victoria Hollis, and Andrew Guydish. 2016. 'Don' t Waste My Time': Use of Time Information Improves Focus. In Proceedings of the 2016 CHI Conference on Human Factors in Computing Systems. ACM, New York, 1729-1738.

[196] Isaac Wiafe and Keiichi Nakata. 2012. Bibliographic analysis of persuasive systems: techniques, methods and domains of application. In Persuasive Technology: Design for Health and Safety; The 7th International Conference on Persuasive Technology. 61-64.

[197] Christopher D. Wickens. 1980. The structure of attentional resources. Atten and performance VIII 8 (1980).

[198] Katie Witkiewitz and G. Alan Marlatt. 2004. Relapse prevention for alcohol and drug problems: That was zen, this is tao. American Psychologist 59, 4 (2004), 224-235. https://doi.org/10.1037/0003-066X. 59.4.224

[199] Troy Wolwerton. 2018. Apple's Tim Cook says he's also spending too much time with his phone. http://uk.businessinsider.com/appleceo-tim-cook-used-new-company-tools-to-track-his-phone-use2018-6

[200] Wendy Wood and Dennis Rünger. 2016. Psychology of Habit. Annual Review of Psychology 67, 1 (2016), 289-314. https://doi.org/10.1146/ annurev-psych-122414-033417

[201] Tim Wu. 2016. The Attention Merchants: The Epic Scramble to Get Inside Our Heads. Knopf Publishing Group.

[202] Xiaomeng Xu, Kathryn E Demos, Tricia M Leahey, Chantelle N Hart, Jennifer Trautvetter, Pamela Coward, Kathryn R Middleton, and Rena R Wing. 2014. Failure to replicate depletion of self-control. PLoS ONE 9, 10 (2014), e109950. https://doi.org/10.1371/journal.pone. 0109950

[203] Lucy Yardley, Tanzeem Choudhury, Kevin Patrick, and Susan Michie. 2016. Current Issues and Future Directions for Research Into Digital Behavior Change Interventions. American fournal of Preventive Medicine 51, 5 (2016), 814-815. https://doi.org/10.1016/j.amepre.2016. 07.019

[204] K.S. S Young. 1998. Internet Addiction: the Emergence of a New Clinical Disorder. CyberPsychology and Behavior 1, 3 (1998), 237-244. http://online.liebertpub.com/doi/abs/10.1089/cpb.1998.1.237

[205] Kimberly S Young. 1999. Internet addiction: Symptoms, evaluation, and treatment. In Innovations in Clinical Practice (Volume 17), L. VandeCreek and T. L. Jackson (Eds.). 19-31. https://doi.org/10.1007/s10879009-9120-x

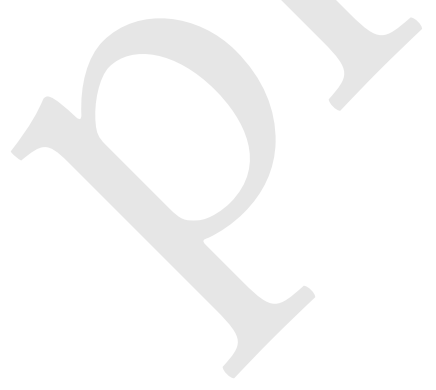

